Original Research Paper

\title{
Soft Sensors for Monitoring Combustion Quality and Flue Gas Emissions in Power Station Boilers
}

\author{
${ }^{1}$ Nallamilli P G Bhavani, ${ }^{2}$ Kesavan Sujatha and ${ }^{1}$ Ponmagal Rajendran \\ ${ }^{I}$ Department of EEE, Center for Electronics Automation and Industrial Research (CEAIR), \\ Dr. M.G.R. Educational and Research Institute, Chennai, India \\ ${ }^{2}$ Deprtment of CSE, Dr. M.G.R. Educational and Research Institute, Chennai, India
}

Article history

Received: 15-02-2014

Revised: 28-01-2017

Accepted: 27-01-2018

Corresponding Author: Kesavan Sujatha

Department of EEE/CSE, Center for Electronics

Automation and Industrial

Research (CEAIR), Dr. M.G.R.

Educational and Research

Institute, Chennai, India

Email: drksujatha23@gmail.com

\begin{abstract}
This research work includes a combination of Fisher's Linear Discriminant (FLD) analysis by merging Radial Basis Function (RBF) Network and Back Propagation Algorithm (BPA) for monitoring the combustion conditions of a coal fired boiler. The CCD Camera is used to capture the two dimensional flame images. The features such as images, average intensity, area, brightness and orientation etc., of the flame are extracted after pre-processing the images. The FLD is applied to reduce the $\mathrm{n}$-dimensional feature size to 2 dimensional feature size for faster learning of the RBF network. Also video processing has been done to extract three classes of images corresponding to different burning conditions of the flames. For various flame conditions, the corresponding temperatures and flue gas emissions are obtained using analyzers and sensors. The combustion quality indicates the air/fuel ratio which can be varied automatically. The proposed feed forward control scheme presents an alternative for the existing set-up for measuring $\mathrm{SOx}, \mathrm{NO}_{\mathrm{x}}, \mathrm{CO}$ and $\mathrm{CO}_{2}$ emissions that are detected from the samples collected at regular intervals of time in the laboratory or by using gas analyzers. Further training and testing of Parallel architecture of Radial Basis Function and Back Propagation Algorithm (PRBFBPA) with the data obtained has been done and the performance of the algorithms is presented.
\end{abstract}

Keywords: Flame Image, Radial Basis Function Network, Back Propagation Network, Fisher's Linear Discriminant, Temperature Monitoring, Monitoring Flue Gas Emissions, Combustion Quality, Parallel Architecture

\section{Introduction}

The boiler converts the chemical energy available in the fuel (coal) into internal energy of steam, the working fluid. The boiler feed water pumps deliver feed water to the boiler drum from where water is directed into the down comers and the circulating pumps located at the bottom of the boiler. The circulating pumps deliver the feed water to the distribution headers beneath the furnace sections. The water rises in the circuits, which are the vertical enclosing walls of the furnace. During combustion, the water walls absorb radiant heat in the furnace (Sujatha et al., 2014) as shown in Fig. 1, boiling take place and a water-steam mixture (saturated steam) enters the drum, while the saturated water leaves the drum and enters the down comers (Sujatha, 2012).

Burning takes place when fuel, most commonly a fossil fuel, reacts with the oxygen in the air to produce heat. The heat created by burning the fossil fuel is used in the operation of boilers, furnaces, kilns and engines. Along with the heat, carbon dioxide $\left(\mathrm{CO}_{2}\right)$ and water $\left(\mathrm{H}_{2} \mathrm{O}\right)$ are created as by-products of the exothermic reaction (Sujatha, 2012).

By monitoring and regulating some of the gases in the stack or exhaust, it is easy to improve the combustion efficiency, which conserves fuel and lowers operation cost (Er et al., 2002. Combustion efficiency deals with the calculation of how effectively the combustion process takes place. To achieve the highest levels of combustion efficiency, complete combustion should take place. Complete combustion occurs when all the energy in the fuel being burnt is extracted and none of the carbon and hydrogen compounds are left unburnt (Sujatha, 2012). Complete combustion will occur when proper amounts of fuel and air (fuel/air ratio) are mixed in correct proportion under the appropriate conditions of turbulence and temperature. 


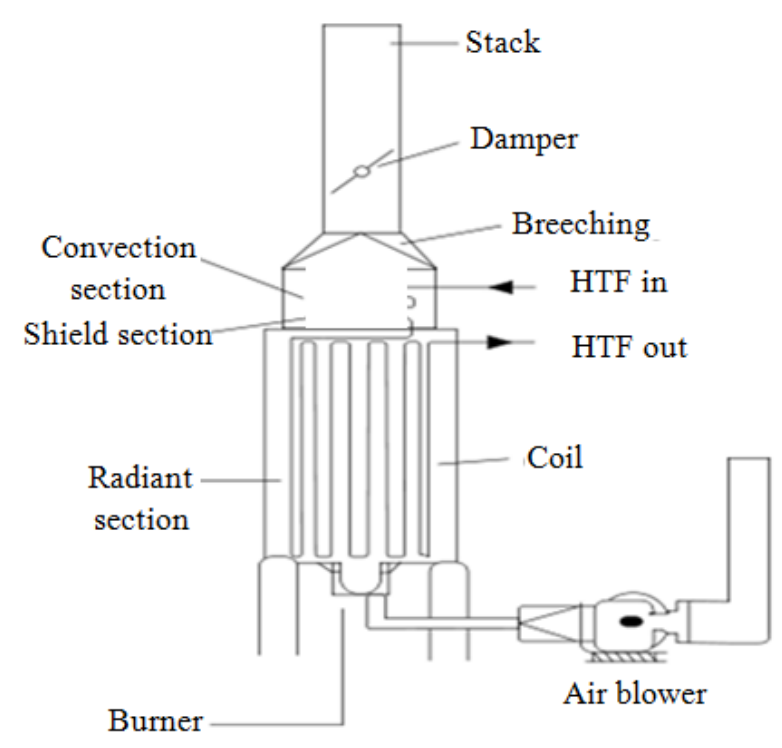

Fig. 1: Schematic diagram of a furnace

Although theoretically stoichiometric combustion provides the perfect air to fuel ratio, which results in lowering the losses and extracting all the energy from the fuel, In reality, stoichiometric combustion is unattainable due to many factors that are varying with respect to time (Lu et al., 2005). Heat losses are inevitable thus making cent percent efficiency impossible. In practice, to achieve complete combustion, it is necessary to increase the amount of air so as to ensure the complete burning of all the fuel. The amount of air that must be added to make the combustion complete is known as excess air. In most of the combustion processes, some additional chemicals are formed during the combustion reactions. Some of the products as a result of combustion process are Carbon monoxide (CO), Nitric Oxide (NO), Nitrogen dioxide $\left(\mathrm{NO}_{2}\right)$, Sulphur dioxide $\left(\mathrm{SO}_{2}\right)$, soot and ash. These flue gas emissions should be minimized and accurately measured. The EPA has set specific standards and regulations for emissions of these products, as they are harmful to the environment. Combustion analysis is a vital step to properly operate and control any combustion process in order to obtain the highest combustion efficiency accompanied by low flue gas emissions (Sujatha, 2012).

\section{Previous Research}

The Maximum Posterior Marginal method (MPM) based on Hidden Markov Model (HMM) for recognition and classification of flame images were used to identify the complete combustion conditions.
Another method based on edge detection and pattern recognition to identify the combustion conditions is also available. Even though it is possible to detect the flame temperature these techniques do not give information regarding the $\mathrm{CO}_{2}$ and $\mathrm{NO}_{x}$ emissions in flue gases thereby providing a poor control of air/fuel ratio (Sujatha and Kalavani, 2011).

The main objective is to design a expert flame monitoring system with progressive cameras, along with artificial intelligence techniques to identify flame features (Sujatha and Pappa, 2011a) that can be correlated with air/fuel ratio, $\mathrm{NO}_{\mathrm{x}}, \mathrm{CO}, \mathrm{CO}_{2}$ emission levels, temperature, etc. The $3 \mathrm{D}$ temperature profiler is designed to provide control of furnace and flame temperature which also reduces the flue gas emissions which is the key in achieving high combustion quality (Sujatha and Pappa, 2011a). The system is also designed to provide guidance for balancing air/fuel ratio so as to ensure complete combustion. The goal ofon-line monitoring and controlled combustion is to address everincreasing demands for higher furnace efficiency, reduced flue gas emissions and improved combustion quality (Sujatha and Pappa, 2011a). These systems, are based on the latest optical sensing and digital image processing techniques (Sujatha and Pappa, 2011a), are capable of determining geometry (size and location), i.e., the geometry of the burner (fixed), luminous (brightness and uniformity) and fluid-dynamics parameters (temperature) of a flame. In the current set up, based on the oxygen content in the exhaust gas the air/fuel ratio of the ratio controller is varied manually in a feedback manner. The proposed scheme can be used to dynamically vary the air/fuel ratio based on the colour of the flame images (feed forward control). An intelligent feed forward control to adjust the air/fuel ratio and to minimize the flue gas emissions for ensuring complete combustion using flame image analysis was implemented. The systems have been evaluated on both laboratory and industrial scale combustion rigs under varied operating conditions.

The features extracted are filtered (median filter, average filter and self adaptive filters) to enhance the flame images that are used for testing the performance of the Self-Organizing feature Maps (SOM) which classifies the flame images as proposed by Fan Jiang et al (2009). Advanced flame and temperature measurement techniques include Laser Raman (LR)/Laser Rayleigh Scattering (RS), Fourier Transform Infrared (FTIR) Spectroscopy and interferometry along with the traces of smoke, small particles, gas streams and bubbles were used to visualize combustion phenomenon (Sujatha and Pappa, 2011a). 


\section{Hypothesis}

The major findings from this research work are as follows:

$\mathrm{H} 1$ : The combustion quality in power station boilers can be determined from the intensity of the flame images

$\mathrm{H} 2$ : The colour of the furnace flame denotes whether the combustion is complete or incomplete

$\mathrm{H} 3$ : The colour of the furnace flame in turn denotes the flue gases at the exhaust. The core of the fire ball is yellowish white during complete combustion

$\mathrm{H} 4$ : Under complete combustion conditions the amount of flue gases like $\mathrm{NO}_{\mathrm{x}}, \mathrm{SO}_{\mathrm{x}}, \mathrm{CO}$ and $\mathrm{CO}_{2}$ emissions are within the tolerance limits

H5: The gas analyzers (Offline) used for measurement of various flue gases can be replaced by intelligent algorithms (Online)

H6: This image processing based flame monitoring system minimizes flue gas emissions at the furnace level thereby ensuring complete combustion

\section{Research Methodology}

The combustion takes place in the furnace when fuel and air get mixed up in proper ratio. The next monitoring point in the flue gas path is the temperature at the exit of the boiler. Flames are generated in the furnace when fuel and air from separated conduits are mixed up in a proper ratio. The flames generated are turbulent and can be looked straight and well-defined, which also refers to the flame oscillation. The temperatures of flame measured by thermocouples are the average values (Han et al., 2006) and the images of the flame will give instantaneous temperatures. Table 1 gives the specifications of the boiler at Neyveli Lignite Corporation (NLC) Ltd.

Also, combustion monitoring involves boiler performance and optimization. The necessity to condition monitor the flame is to control emissions of Nitrogen Oxide $\left(\mathrm{NO}_{\mathrm{x}}\right)$, Carbon monoxide $(\mathrm{CO})$, Carbon dioxide $\left(\mathrm{CO}_{2}\right)$, increased fuel efficiency and improved burner reliability to maintain required furnace temperature (Lipmann et al., 1987). When the air to fuel ratio is incorrect, $\mathrm{NO}_{\mathrm{x}}, \mathrm{CO}_{2}$ and $\mathrm{CO}$ emissions will increase at the outlet which in turn influences the flame temperature. For efficient combustion of different fuels the quality of the flame must be maintained in order to reduce air pollution and fuel consumption. Burner imbalances in coal, oil and air which results in low combustion efficiency, elevated emissions of Nitrogen oxides $\left(\mathrm{NO}_{\mathrm{x}}\right)$, Carbon monoxide $(\mathrm{CO})$, localized reducing conditions and promotion of slag formation. Differences from one burner to the next in combustion conditions are due to factors such as imbalances in air/fuel ratio and maintenance problems at individual burners. The existing set-up indicates only the presence or absence of the flame in the furnace (Han et al., 2006).
Table 1: Boiler data-neyveli lignite corporation

\begin{tabular}{ll}
\hline Parameters & Specifications \\
\hline Type & Radiant tower \\
Circulation & Natural \\
Manufacture & Ansaldo Energia \\
Boiler Design Pressure & $182 \mathrm{~kg} / \mathrm{cm}^{2}(\mathrm{a})$ \\
Fuel & Lignite \\
Start-up fuel & Light Diesel Oil-Heavy Fuel oil \\
Burners type & Tangential Firing \\
Number of burners & 12 Lignite and 8 Fuel oil burners \\
Mills type & Ventilation Mill MB 3400/900/490 \\
Number of Mills & 6 numbers \\
SH Flow at outlet & $540 \mathrm{t} / \mathrm{hr}$ \\
Temperature SH at outlet & $540 \mathrm{degree}$ Celsius \\
Lignite fired-Best & $189 \mathrm{t} / \mathrm{hr}$ \\
Lignite fired-Average & $213 \mathrm{t} / \mathrm{hr}$ \\
Lignite fired-worst & $230 \mathrm{t} / \mathrm{hr}$ \\
\hline
\end{tabular}

\section{Hypothesis Testing}

\section{Intelligent Flame Monitoring System}

The schematic diagram for the proposed work is shown in the Fig. 2. The images are extracted from the video. The features are extracted (Sujatha et al., 2014) from each image. Fisher's linear discriminant function reduces the dimensions of extracted features (Sujatha and Pappa, 2011a) into 2 dimensions (Sujatha, 2012). The RBF (Sujatha and Pappa, 2010; Sujatha and Pappa, 2011 ) is trained with the 4 feature vectors generated from 3 groups of images and similarly the BPA is also trained with remaining 3 feature vectors. The final output from these two networks is once again given as input to another network trained using RBF (Purushothaman, 2009). The target values are the temperature of each group of images, the measured $\mathrm{CO}$, $\mathrm{CO}_{2}, \mathrm{SO}_{\mathrm{x}}$ and $\mathrm{NO}_{\mathrm{x}}$ values from the flue gas. In the test phase, the outputs of proposed algorithms are compared with the measured values of flue gas to decide if any adjustment in the air/fuel ratio is required for a burner.

\section{Conventional Vs Intelligent Flame Monitoring System}

The Table 2 shows the quality of coal supplied which is dependent on the moisture and ash content. The velocity of the pulverized coal/air/gas mixture at the burner nozzle outlet is $12-14.4 \mathrm{~m} / \mathrm{sec}$. The flame images are obtained from the control room of the thermal power plant boiler. Table $3 \mathrm{a}-\mathrm{c}$ shows the samples of flame images and the corresponding measurements of flue gases and flame temperature. Totally 102 flame images gathered. Of this 51 images for training and 51 images for testing the proposed algorithm were taken into consideration. Class 1 (flamel to flame 18), class 2 (flame 19 to flame 38) and class 3 (flame 39 to flame 51) are of importance from the control room. Cropping of each image is done to the size of $30 \times 30$ pixels but any other size could also be chosen. 


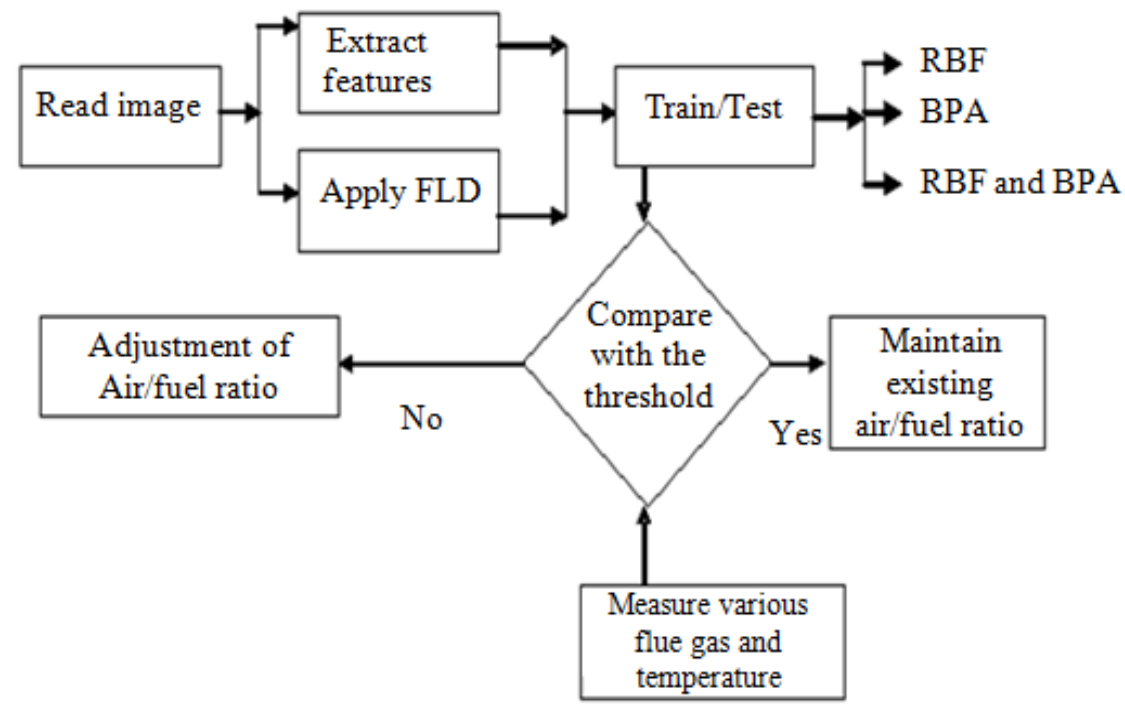

Fig. 2: Schematic diagram for flame image analysis and intelligent classification

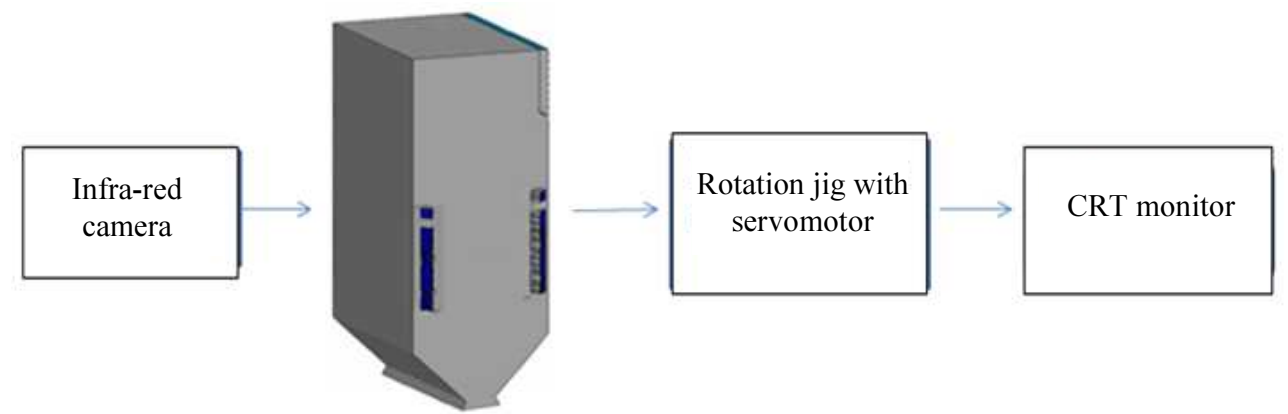

(a)

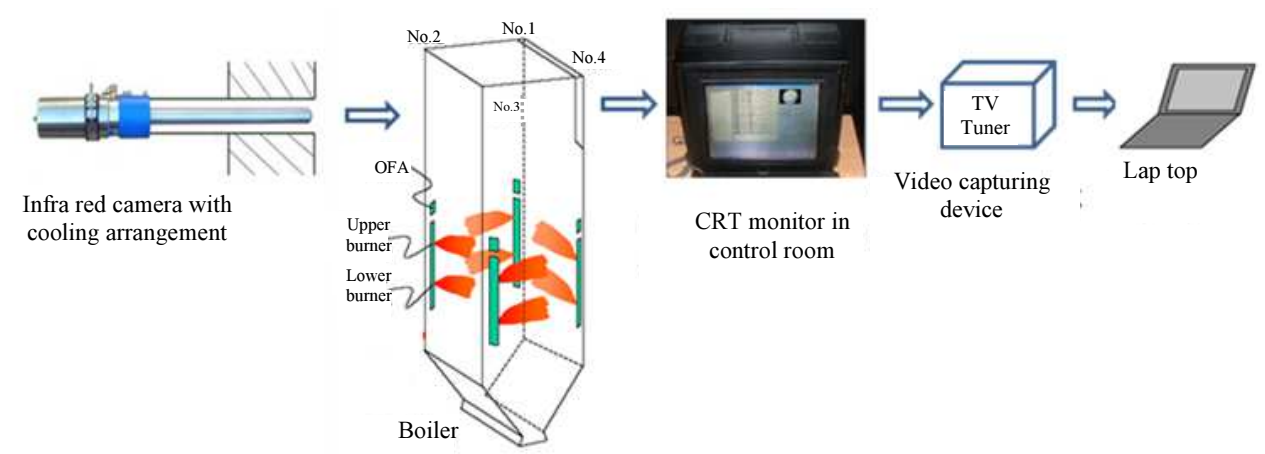

(b)

Fig. 3a: Existing arrangement for flame monitoring system at Neyveli Lignite Corporation (b) Proposed arrangement for intelligent flame monitoring system

Table 2: Coal characteristics under normal operating conditions

\section{Parameters}

Net Calorific Value

Moisture (M)

Ash (A)
Average values $2350 \mathrm{kcal} / \mathrm{kg}$

$52 \%$

$6 \%$ 
Table 3a: Flame Images for combustion categories

Combustion category
Complete combustion
Partial combustion
Incomplete combustion

Table 3b: Measurement data for different combustion categories

\begin{tabular}{llll}
\hline Combustion category & & Temperature of superheated \\
Steam in (degree Celsius) & Combustion quality $(\%)$ \\
\hline Class 1 Complete combustion & 400 & 530 & 100 \\
Class 2 Partial combustion & 600 & 240 & 50 \\
Class 3 Incomplete combustion & 900 & 170 & 30 \\
\hline
\end{tabular}

Table 3c: Measurement data for different combustion categories

\begin{tabular}{llll} 
& & & \\
$\mathrm{NO}_{\mathrm{x}} \mathrm{mg} / \mathrm{Nm}^{3}$ & $\mathrm{CO} \mathrm{ppm}$ & $\mathrm{CO}_{2} \mathrm{Nm}^{3} / \mathrm{hr}$ & $\begin{array}{l}\text { Flame temperature } \\
\text { in }(\text { degree Celsius })\end{array}$ \\
\hline 70 & 100 & 400 & 1250 \\
120 & 200 & 700 & 900 \\
200 & 300 & 1000 & 300 \\
\hline
\end{tabular}

The $\mathrm{CO}, \mathrm{NO}_{\mathrm{x}}, \mathrm{CO}_{2}, \mathrm{SO}_{\mathrm{x}}$ values and air/fuel ratio measured from the flue gas at the same instant were recorded from the existing set up as shown in Fig. $3 b$. The proposed system for online monitoring is shown in Fig. 3b. The existing set up at NLC is shown in Fig. 3a. The major components of the proposed flame monitoring system are listed here:

- Infra-red camera placed inside a cooling jacket with servo-motor mechanism

- CCTV set up placed in the control room

- TV tuner for transferring the flame video from the CRT monitor on to the PC

- Laptop connected to the TV tuner

- The video file is split up into frames for further analysis

- Image processing algorithms for analyzing the constituents of the flame

- Intelligent control strategy to monitor and control the combustion quality

- Validation of the developed system.

The following stages are involved in the proposed flame video analysis is as shown in Fig. 3b:

Step 1: The video file is further processed by splitting into frames using any video splitter

Step 2: The flame images are pre-processed for noise removal

Step 3: The features are extracted

Step 4: Features are reduced

Step 5: Classification using AI techniques
Step 6: Validation of the algorithms with performance measures

\section{Pre-Processing}

Pre-processing is done to remove noise. The frame size considered for filtering was $30 \times 30$. It is sufficient that the $30 \times 30$ portion of the image is taken for further analysis. The extracted flame images if corrupted with noise, then filtering needs to be done. Filtering was done using Image J. The various filters available are the unsharp mask filter, Maximum filter, Minimum filter, Variance filter. Figure 5 shows the output for various filters listed above and it is evident that median filtering yields better results. It is inferred that the performance of median filter on noise removal was good when compared with the other filters (Sujatha et al., 2011). The mean filter also performs filtering to a certain extent but the clarity of the filtered image is slightly low when compared with the median filter. The other filter types are not suitable because the basic information present in the original image is lost. Hence it is better to use a median filter for noise removal pertaining to this situation.

\section{Edge Detection}

The colour images are converted into corresponding gray scale images to extract the features which are the basic identity of an image. The edge detection based on the threshold is done in order to segregate the region of interest. The gray scale conversion and thresholding was done for all the 51 images. The results of which are shown below in the Fig. 4. 


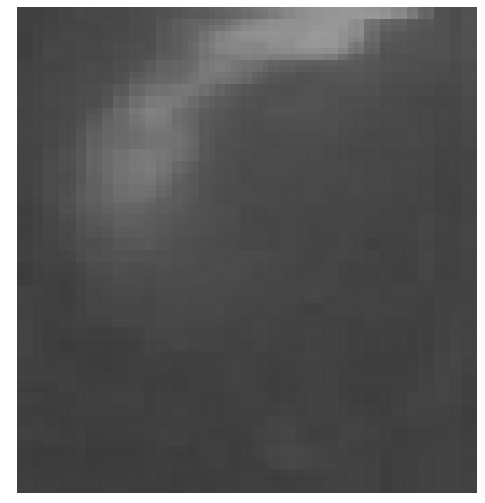

(a)

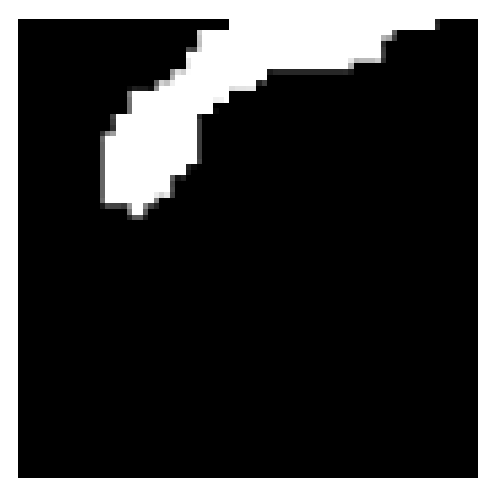

(b)

Fig. 4: Edge detection using Sobel operator (a) Gray Scale image (b) After edge detection

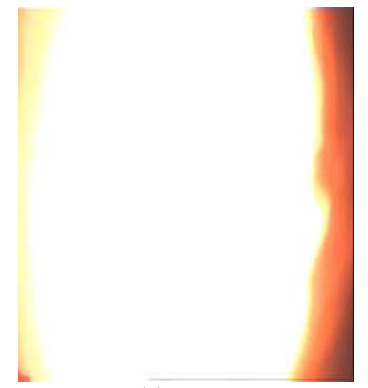

(a)

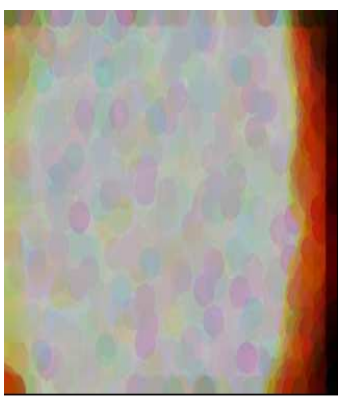

(e)

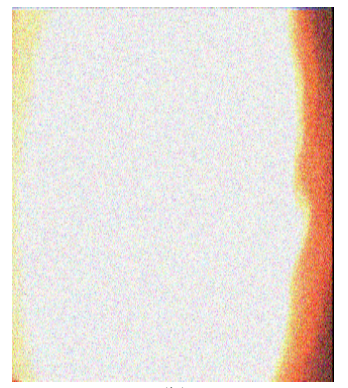

(b)

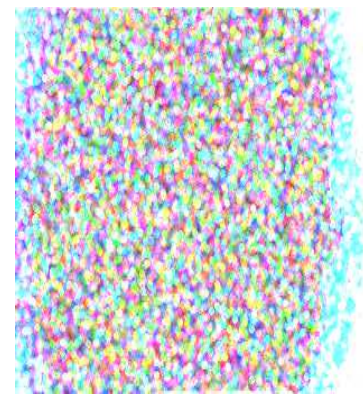

(f)

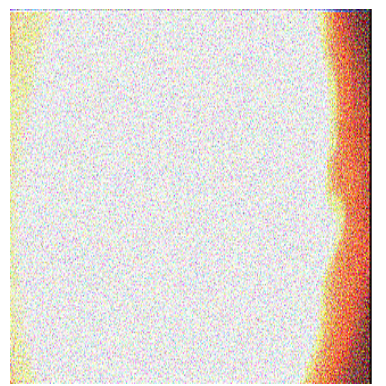

(c)

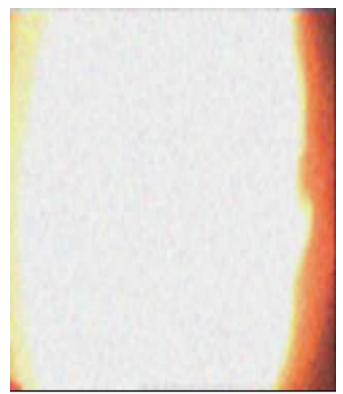

(g) (d)

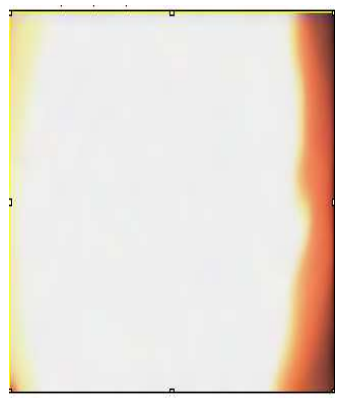

(h)

Fig. 5: Effect of different filtering techniques on the corrupted flame image (a) Original image (b) Corrupted image (c) Unsharp mask filter (d) Maximum filter (e)Variance filter (f) Minimum filter (g) Mean filter (h) Median filter

\section{Feature Extraction}

The features are the basic pattern that gets distributed along various directions in an image. They represent the characteristics of the images. The features extracted are centroid $\mathrm{x}$ and centroid $\mathrm{y}$ of the flame in the image, orientation of the flame, average intensity of the flame image, area (Sujatha et al., 2014) of the flame and the discriminant vectors $\Phi_{1}$ and $\Phi_{2}$ (Sujatha et al., 2013). The target outputs are the temperatures, measured for set of images, the $\mathrm{CO}$ emissions measured in ppm, $\mathrm{NO}_{\mathrm{x}}$ in $\mathrm{mg} / \mathrm{Nm}^{3}, \mathrm{CO}_{2}$ in $\mathrm{Nm}^{3} / \mathrm{hr}, \mathrm{SO}_{\mathrm{x}}$ in $\mathrm{mg} / \mathrm{Nm}^{3}$, in the rate of air supply in $\mathrm{t} / \mathrm{hr}$ and the fuel supplied in $\mathrm{t} / \mathrm{hr}$ (Sujatha et al., 2014).

\section{Classification}

The classification was done using RBF and various parallel architecture of BPA and RBF. The Back Propagation Algorithm (BPA) is a neural network is constructed by highly interconnected processing units (nodes or neurons) which perform simple mathematical operations. Neural networks are characterized by their topologies, weight vectors and activation function which are used in the hidden layers and output layer. The topology refers to the number of hidden layers and connection between nodes in the hidden layers. The activation functions that can be used 
are sigmoid, hyperbolic tangent and sine (Purushothaman and Srinivasa, 1998). The network models can be static or dynamic. Static networks include single layer perceptrons and multilayer perceptrons. A perceptron or Adaptive Linear Element (ADALINE) refers to a computing unit. This forms the basic building block for neural networks. The input to a perceptron is the summation of input pattern vectors by weight vectors. Information flows in a feed-forward manner from input layer to the output layer through hidden layers (Sujatha and Pappa, 2011b; Fisher, 1936). The number of nodes in the input layer and output layer is fixed. It depends upon the number of input variables and the number of output variables in a pattern. In this work, there are seven input variables and one output variable. The number of nodes in a hidden layer is fixed by trial and error. In this application, the network parameters such as the number of nodes in the hidden layers and the number of hidden layers are found by trial and error method. In most of the applications one hidden layer is sufficient. As the name implies Back Propagation Algorithm (BPA) the weight updation takes place in the reverse order i.e., from the output layer to input layer (Sujatha and Pappa, 2010).

The classification was also performed with Radial Basis Function (RBF) classifier. A Radial Basis Function (RBF) is a real-valued function, whose value depends only on the distance from the origin. If a function ' $\mathrm{h}$ ' satisfies the property $h(x)=h(\|x\|)$, then it is a radial function. A Gaussian RBF monotonically decreases with distance from the centre. RBF networks have traditionally been associated with radial functions in a single-layer network. The input layer carries the value of $\phi_{1}$ and $\phi_{2}$. The distance between these values and centre values are found and summed to form linear combination before the neurons of the hidden layer (Sujatha et al., 2015).

These neurons are said to contain the radial basis function with exponential form. The outputs of the RBF activation function is further processed according to specific requirements. The activation function which is used to train the ANN is the Gaussian function (Wojcik, 2008).

The Parallel architecture of Radial Basis Function Network and Back Propagation Algorithm (PRBFBPA) was proposed, since the convergence and the classification performance for the single intelligent networks are not satisfactory the parallel architectures of intelligent classifier are proposed in this study. The outputs of BPA and RBF of the first stage are combined and given as inputs to a second RBF network for final classification of the flame images. The block diagram for PRBFBPA is shown in Fig. 6 below. Similiar structures were used to identify the various flue gas emissions like $\mathrm{CO}, \mathrm{CO}_{2}, \mathrm{SO}_{\mathrm{x}}$ and $\mathrm{NO}_{\mathrm{x}}$ along with air/fuel ratio and flame temperature. The features obtained from flame images are given as the input to the BPA and RBF initially (Fisher, 1936). The architecture for various combinations of the intelligent network is shown in Fig. 6.

\section{Performance Evaluation}

The classification performance of the intelligent classifiers is evaluated using precision and recall. Precision is defined as the ratio of number of all the images retrieved to number of all the relevant images retrieved. Recall is defined as the ratio of number of all the relevant images retrieved to the number of all the images in each group (Sujatha, 2013).

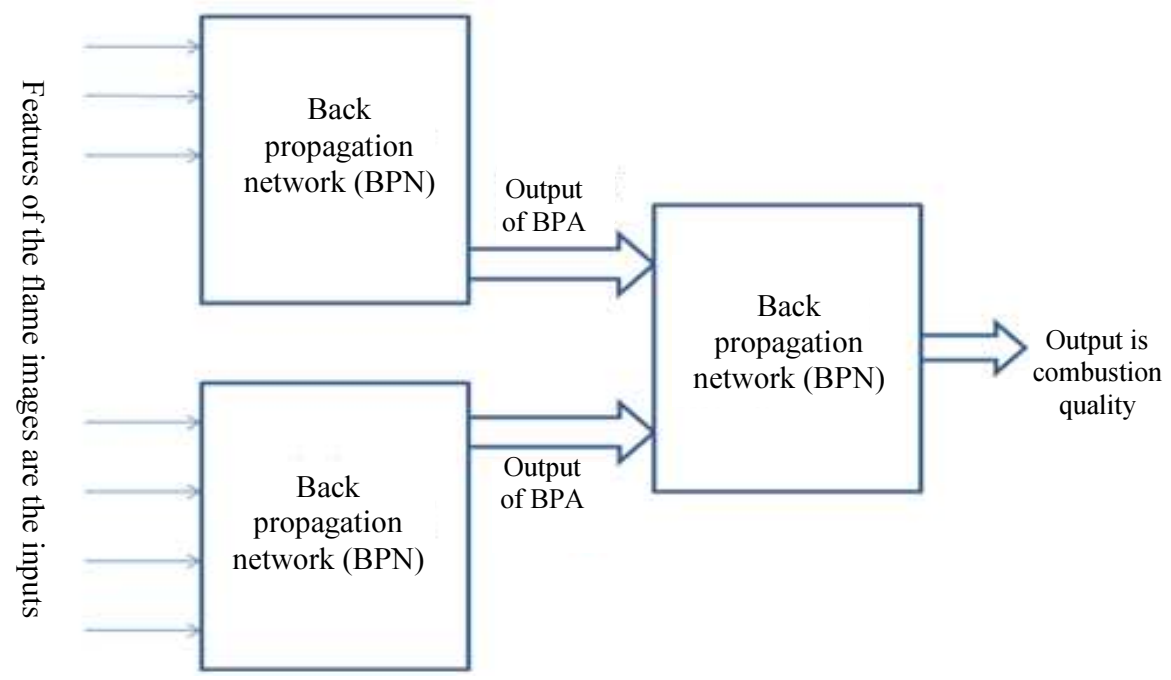




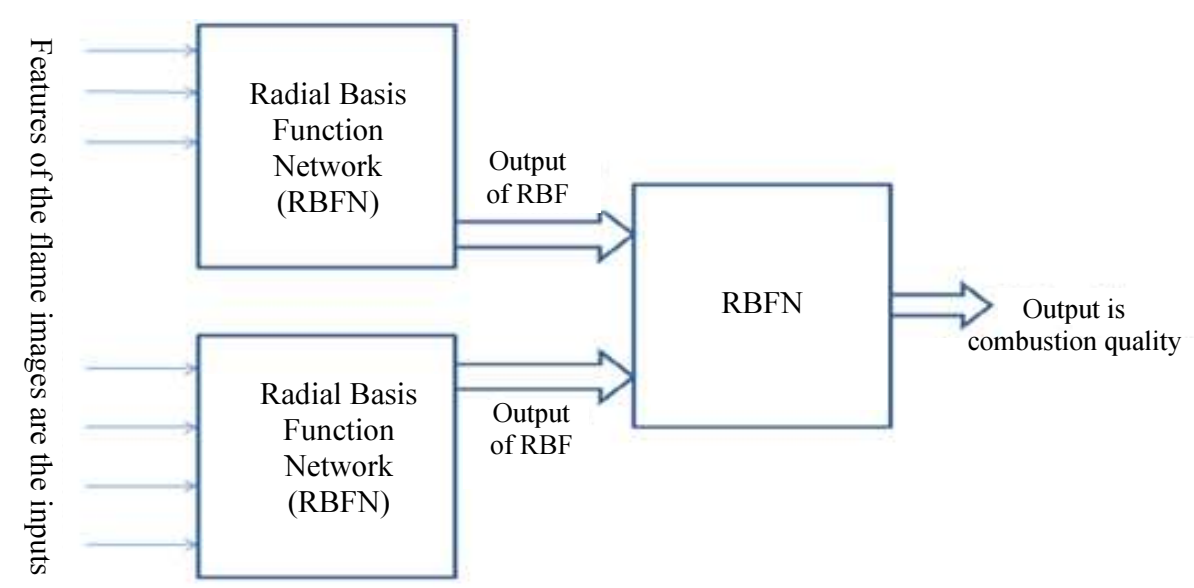

(b)

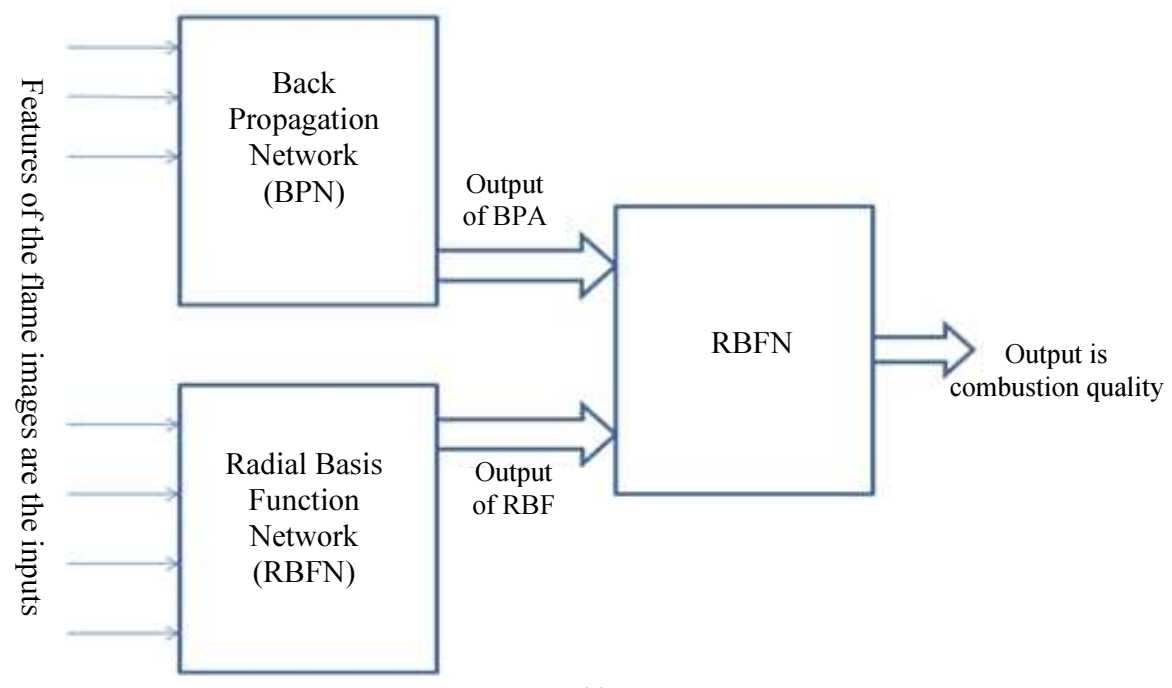

(c)

Fig. 6: Various combination of the intelligent classifiers (a) Architecture for multiple BPA (b) Architecture for multiple RBF (c) Architecture for combined of BPA RBF

\section{Results and Discussion}

\section{Results}

The Fig., 7a-c show the histogram analysis for each class of images. The histogram for class 1 images has high frequency of occurrence corresponding to the intensity value of 255 when compared to class 2 and class 3 images. The Fig. 8a-c show the surface plot for all the three categories discussed earlier. The surface plot for complete combustion in Fig. 8a shows that the entire surface lies near the intensity value 255 about the $\mathrm{Z}$-axis whereas for the other two categories as shown in Fig. 8b and $\mathrm{c}$ the entire surface lies near the intensity of 150 and 20 approximately. Image $\mathbf{J}$ was used to obtain the histogram and surface plots (Jiang et al., 2009).

By the process of FLD, $\varphi_{1}$ and $\varphi_{2}$ discriminant vectors given in Table 3 are obtained by using three categories of flame images. The classification performance of FLD is given in Table 4. The distribution of the 2D patterns by FLD is shown in Fig. 9 above for all the three classes. This distribution is also obtained taking various $30 \times 30$ pixels of the flame image. It is was found that any $30 \times 30$ pixels considered for further analysis will not affect the classification performance (Hong and Yang, 1991).

Similar type of results as shown in Fig. 9 is obtained when considering the different portions of the flame image. The targets are the values of the various flue gas emissions, combustion quality and flame temperature. The normalized values of the features are used for obtaining results from the various intelligent classifiers. For normalization each value of the feature divided by the maximum value of that feature is used as the formula so as reduce the computational complexity (Foley, 1972). 
Kesavan Sujatha et al. / American Journal of Applied Sciences 2018, 15 (1): 95.115 DOI: 10.3844/ajassp.2018.95.115

Table 4: Classification by FLD

\begin{tabular}{llll}
\hline & Number of images & Number of & $\begin{array}{l}\text { Number of } \\
\text { images misclassified }\end{array}$ \\
\hline 1 & used for testing & images classified & 17 \\
2 & 18 & 18 & 2 \\
3 & 20 & 13 & 0 \\
\hline
\end{tabular}

Table 5: Network Parameters for BPA, RBF and PRBFBPA

\begin{tabular}{llll} 
Network parameters & BPA & RBF & PRBFBPA \\
\hline No. of nodes in the input layer & 3 & 4 & 2 \\
No. of nodes in the hidden layer & 6 & 9 & 7 \\
No. of nodes in the output layer & 1 & 1 & 1 \\
No. of patterns for training & 51 & 51 & 51 \\
No. of patterns for testing & 51 & 51 & 51 \\
Mean Squared Error & 0.019 & 0.0391 & 0.0443 \\
Activation function & sigmoid & Gaussian and Linear & Gaussian and Linear \\
\hline
\end{tabular}

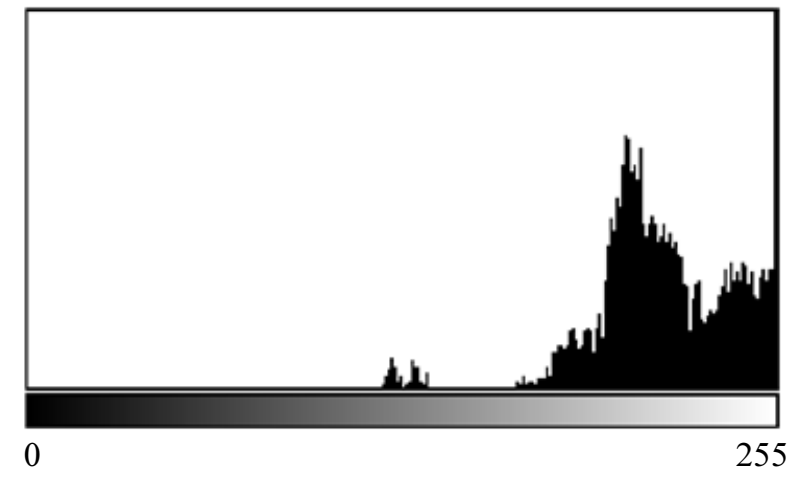

Count: 76800

Mean: 250.114

StdDev: 15.529
Min: 120

Max: 255

Mode: 255 (67368)

(a)

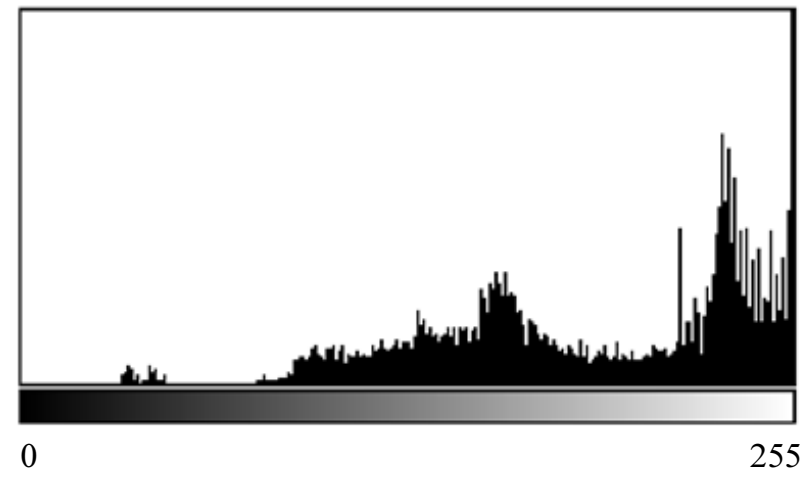

Count: 76800

Mean: 240.648

StdDev: 36.659
Min: 31

Max: 255

Mode: 255 (60934)

(b)

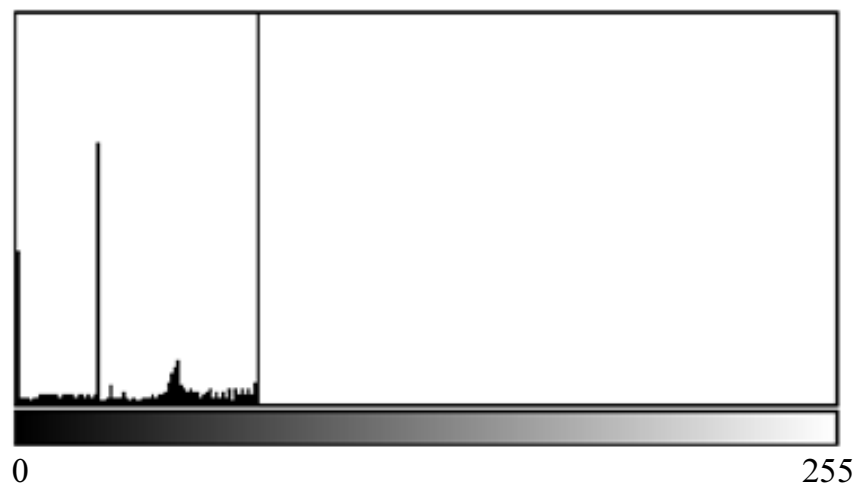

Count: 76800

Mean: 66.132

StdDev: 19.825

Min: 0

Max: 75

Mode: 75 (60367)

(c)

Fig. 7: Histogram Analysis for flame images (a) Complete Combustion (b) Partial Combustion (c) Incomplete Combustion 


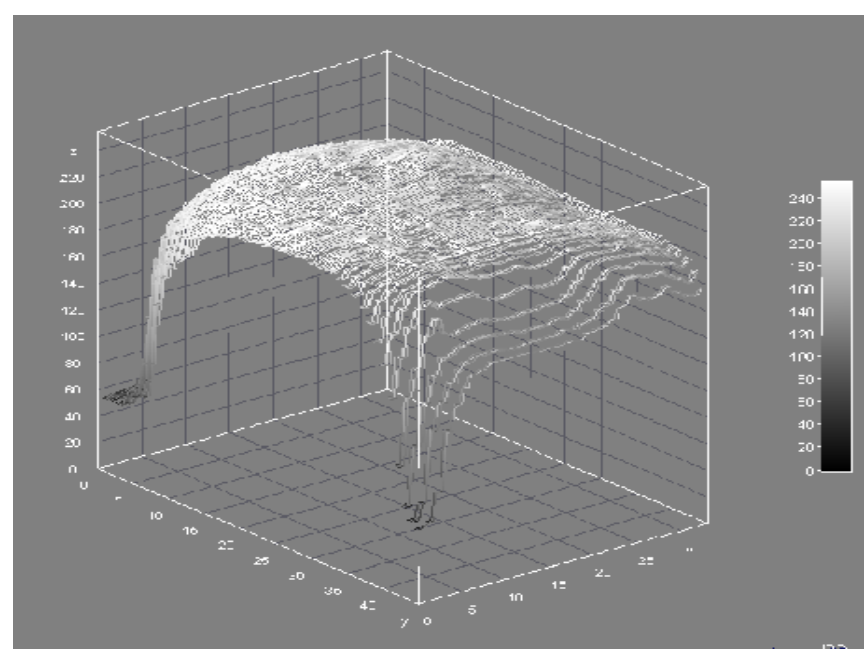

(a)

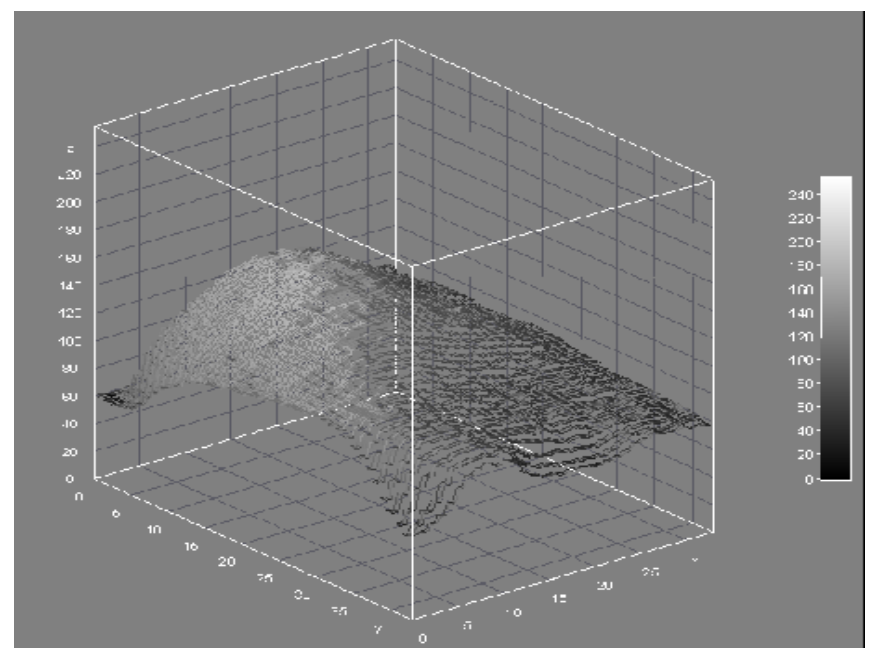

(b)

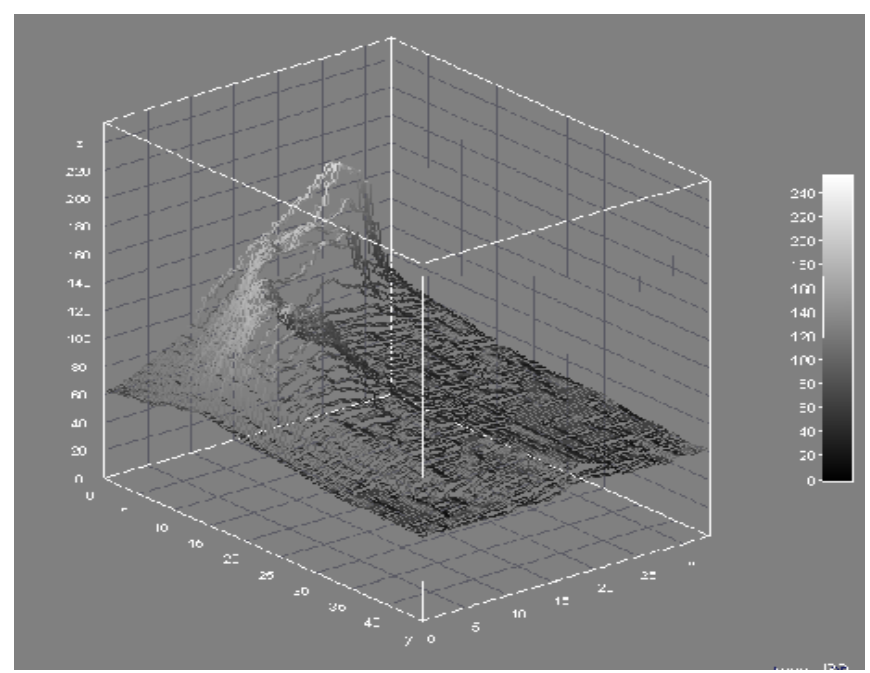

(c)

Fig. 8: Surface Plot of the flame for complete, partial and incomplete combustion (a) Complete combustion Category (b) Partial combustion Category (c) Incomplete combustion Category 


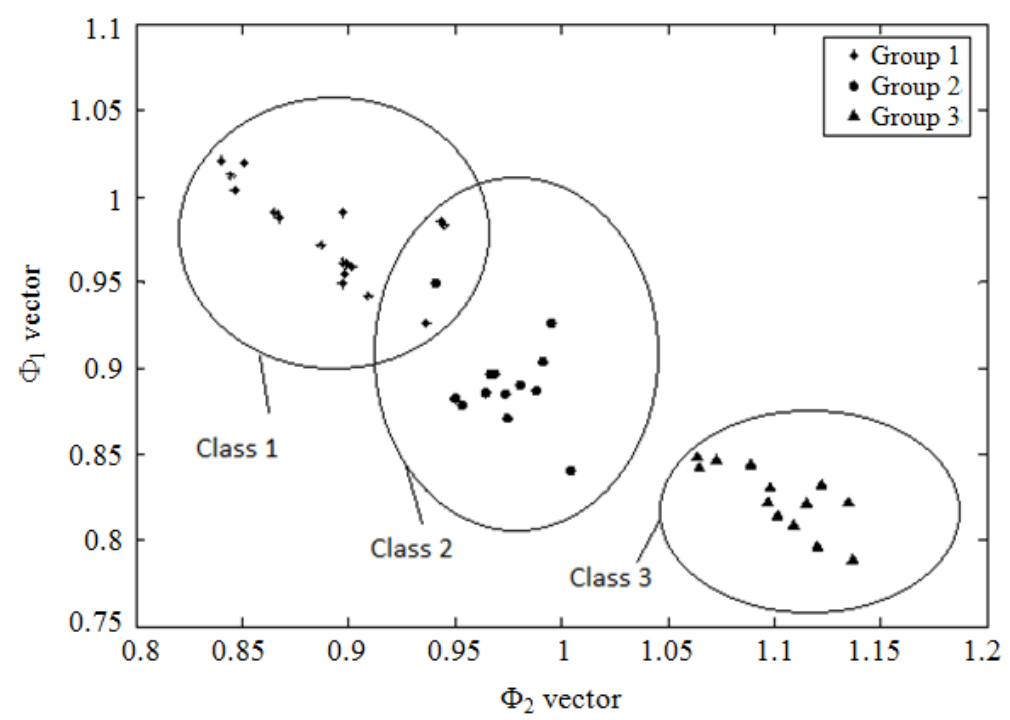

Fig. 9: Distribution of two dimensional patterns of Class 1, Class 2 and Class 3 images for choosing $30 \times 30$ pixels at different portion of the image

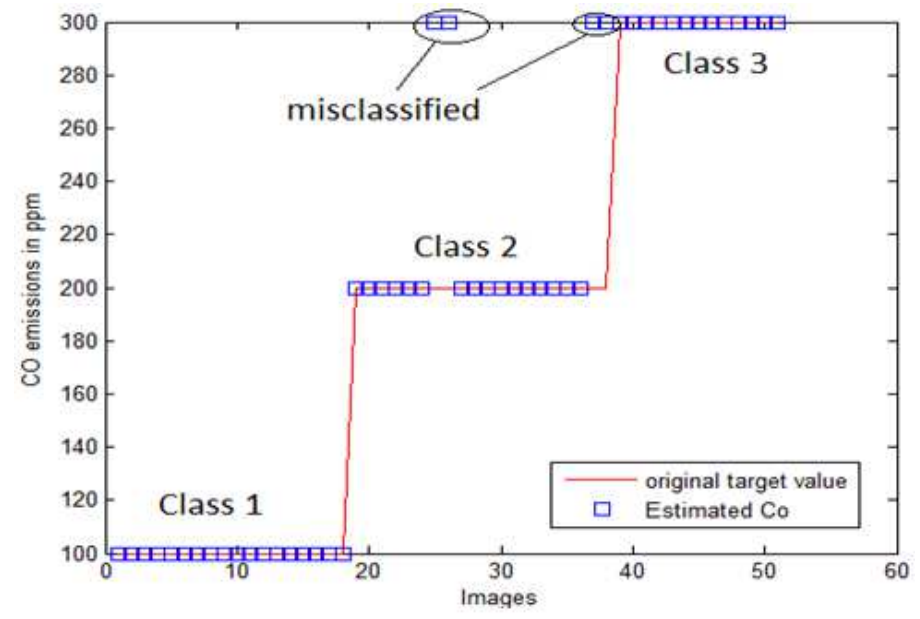

(a)

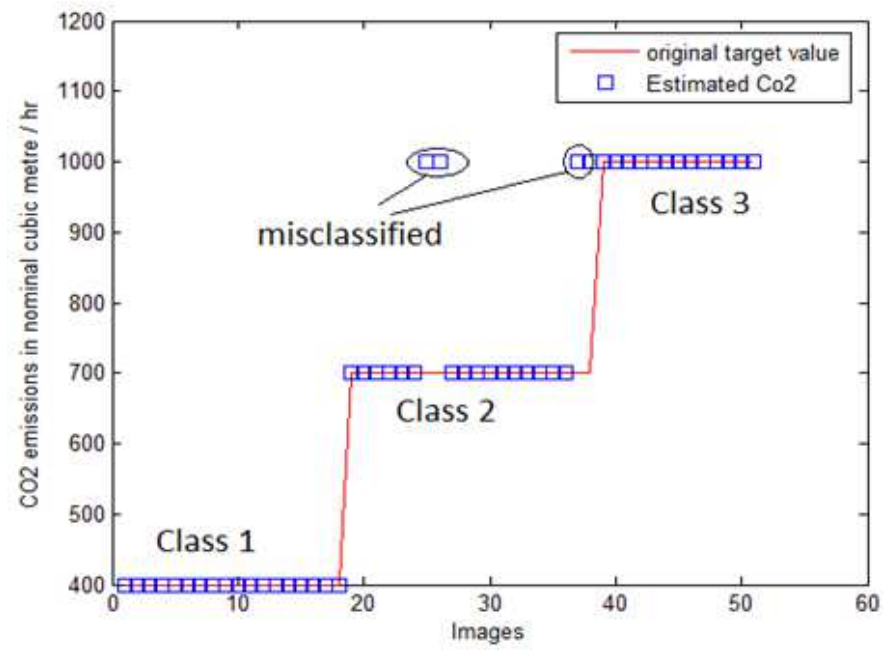

(b) 


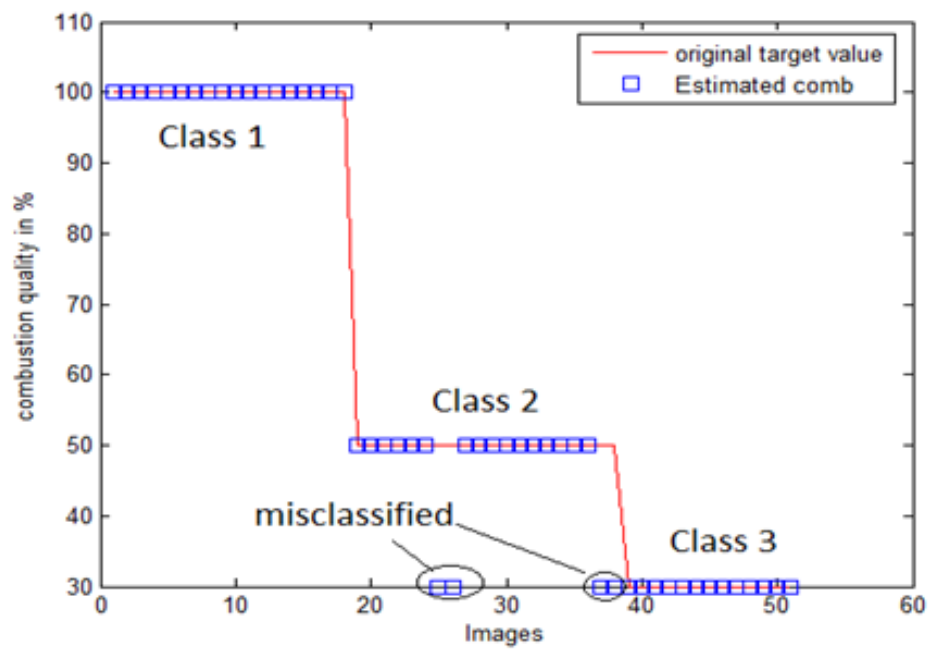

(c)

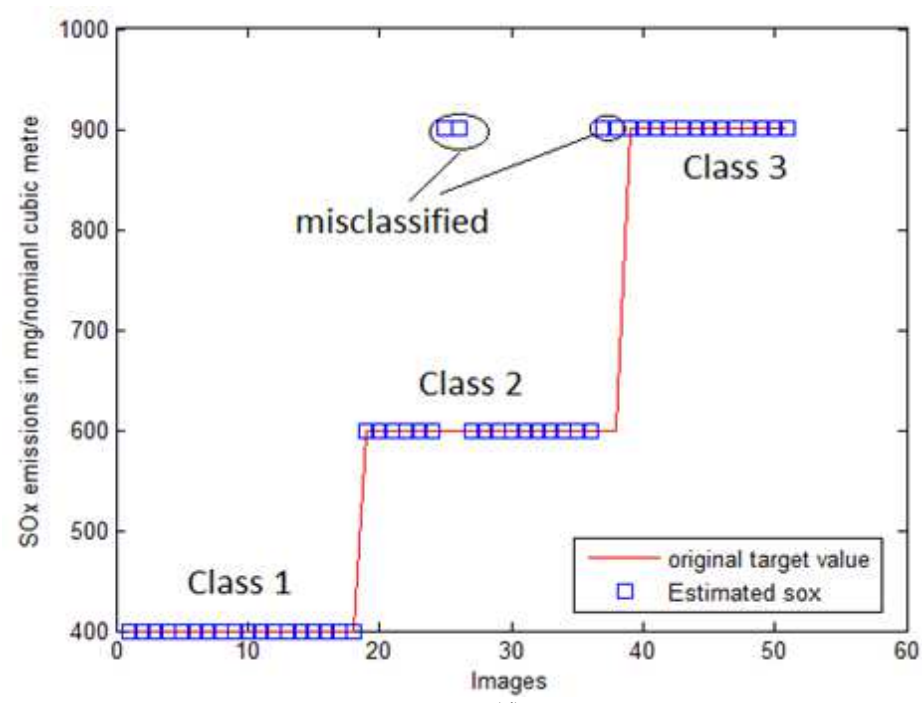

(d)

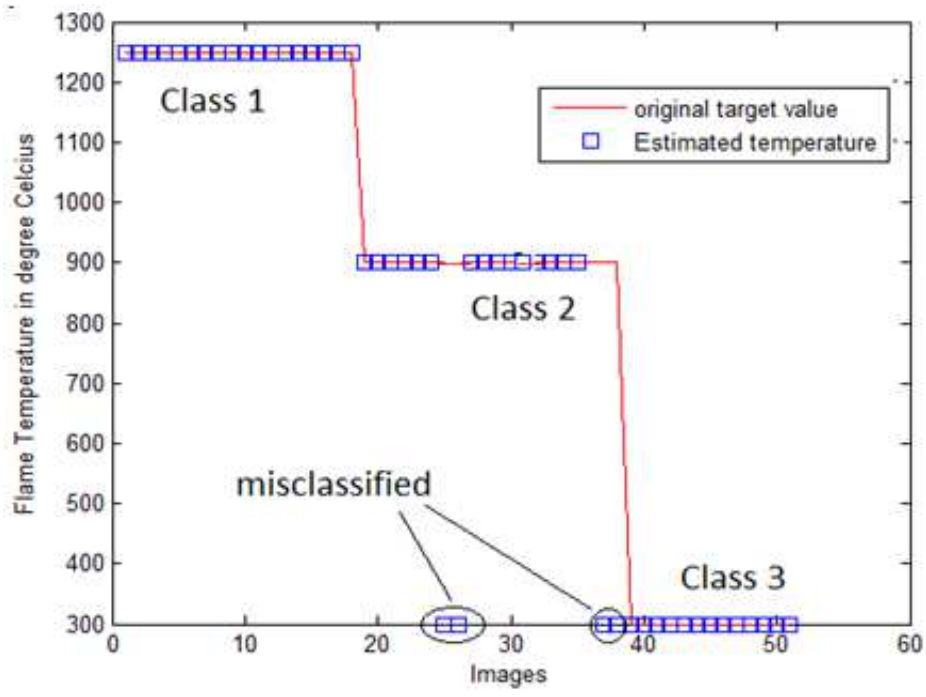

(e) 


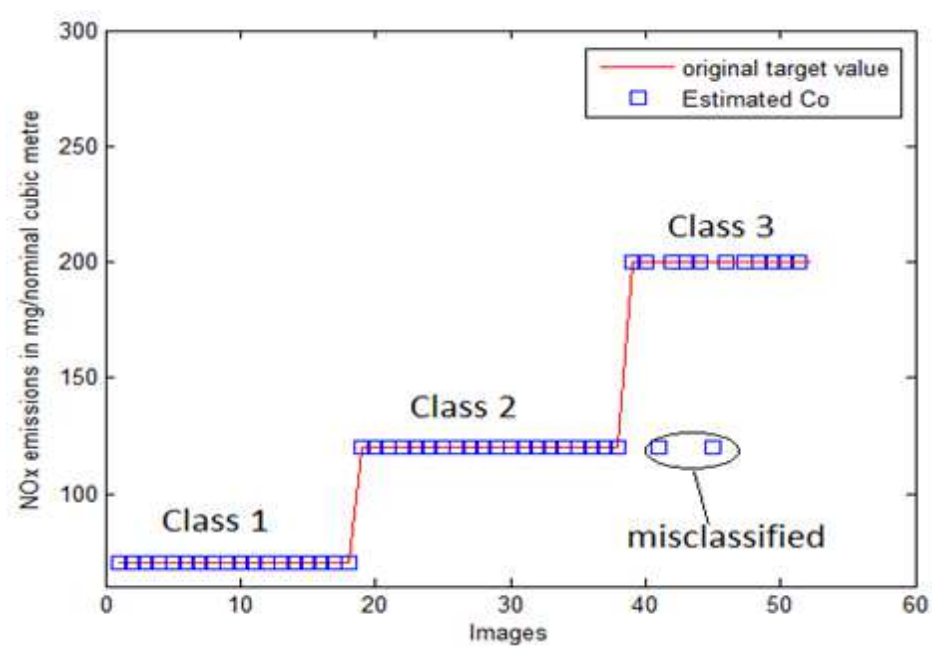

(f)

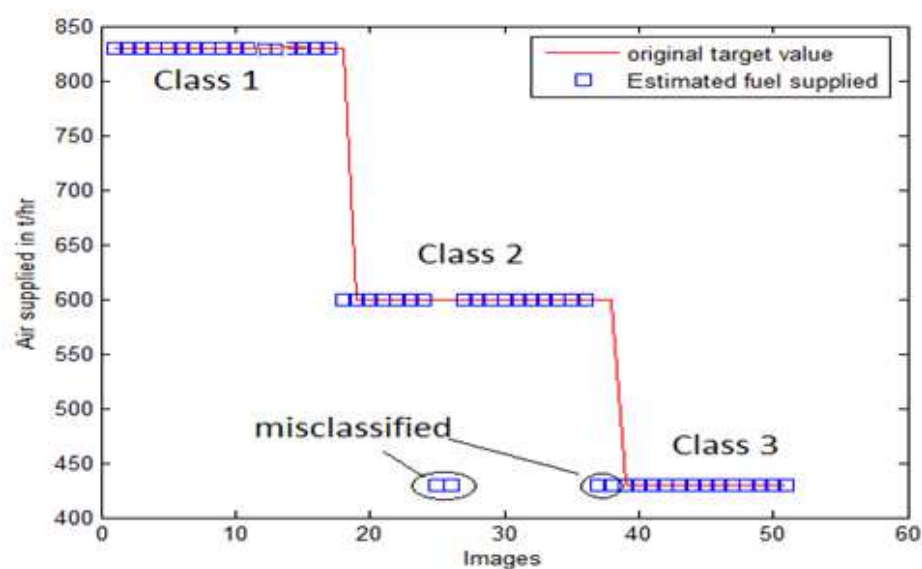

(g)

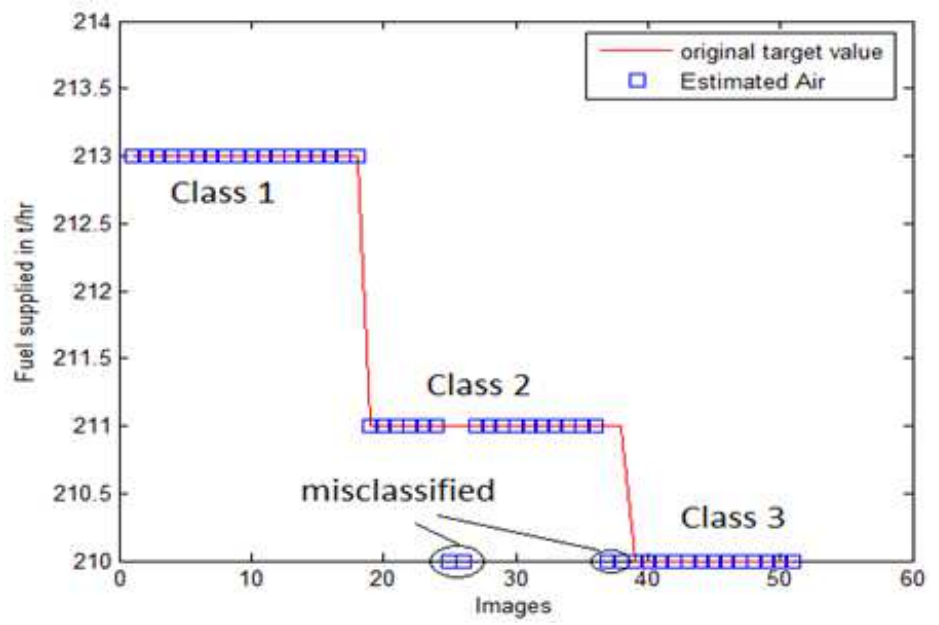

(h)

Fig. 10: Outputs for parallel architecture of BPA and RBF with four features as input to BPA and three features as input to RBF (a). Prediction of $\mathrm{CO}$ emissions by PRBFBPA (b). Prediction of $\mathrm{CO}_{2}$ emissions by PRBFBPA (c). Prediction of Combustion quality by PRBFBPA (d). Prediction of $\mathrm{SO}_{x}$ emissions by PRBFBPA (e).Prediction of Flame Temperature by PRBFBPA (f). Prediction of NOx emissions by PRBFBPA (g). Prediction of Air supplied by PRBFBPA (h). Prediction of Fuel supplied by PRBFBPA 


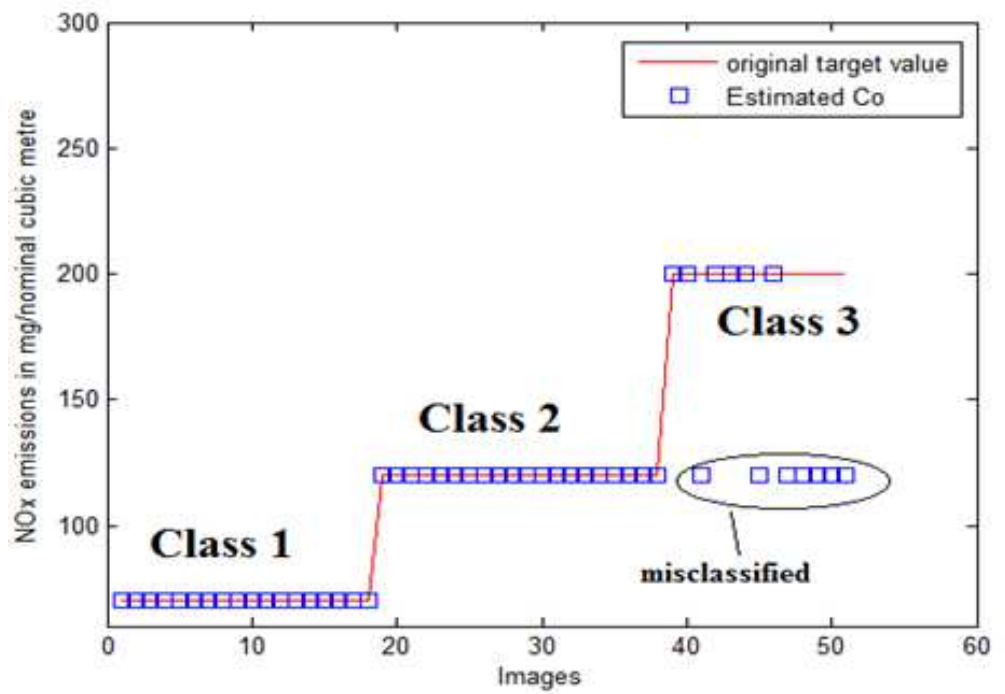

(a)

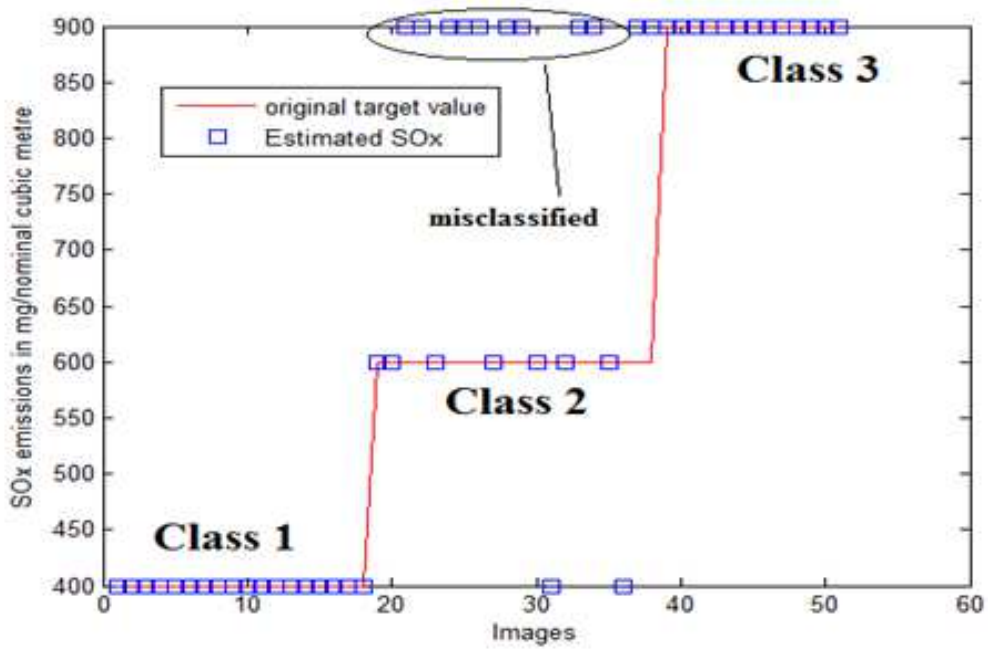

(b)

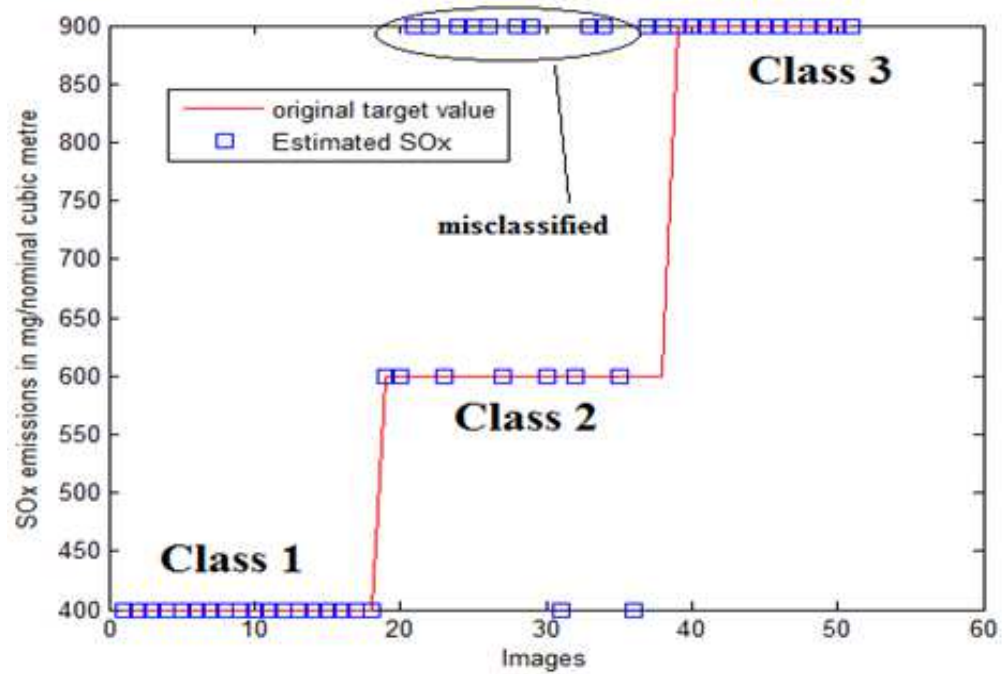

(c) 


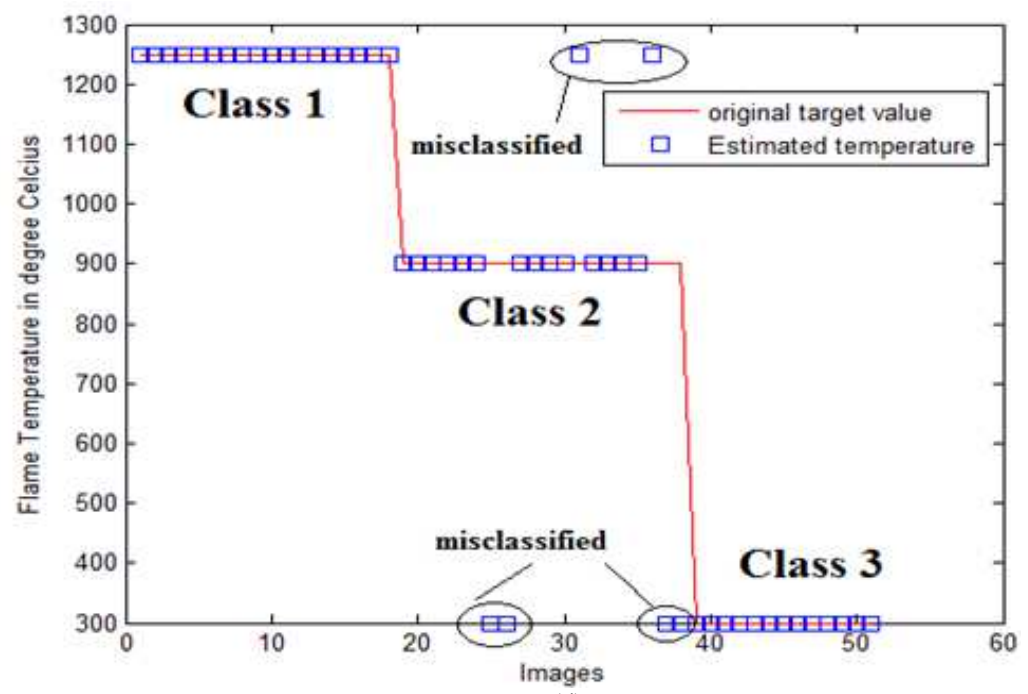

(d)

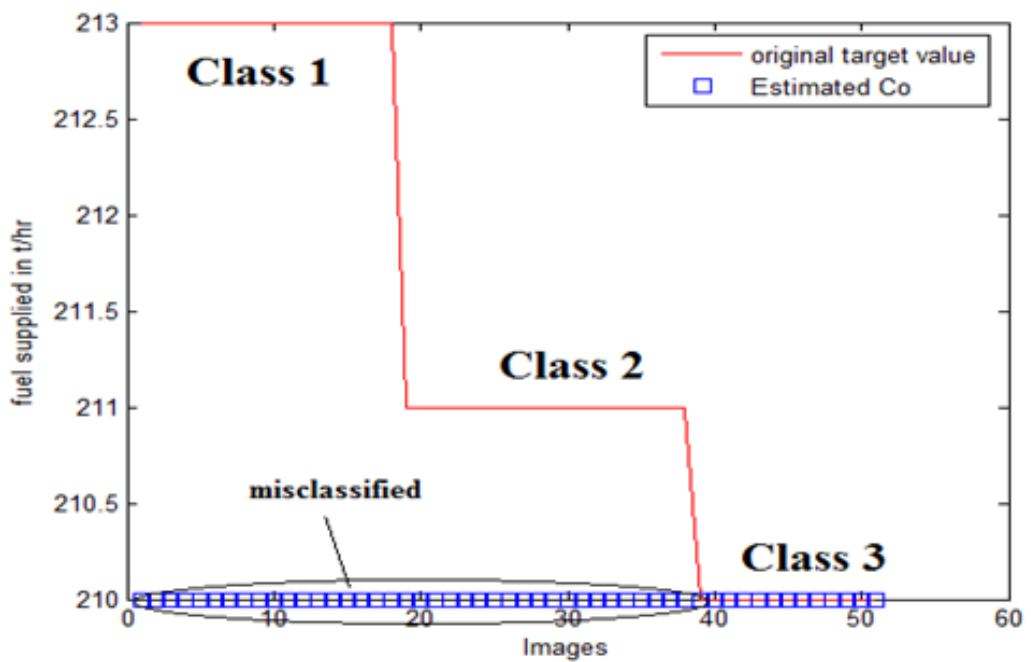

(e)

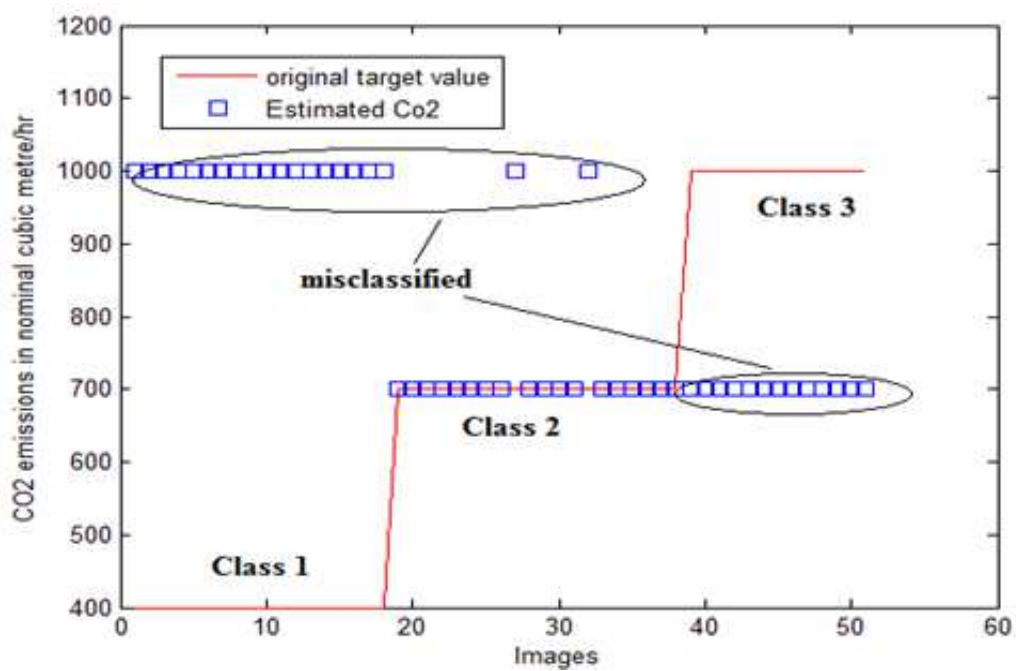

(f) 


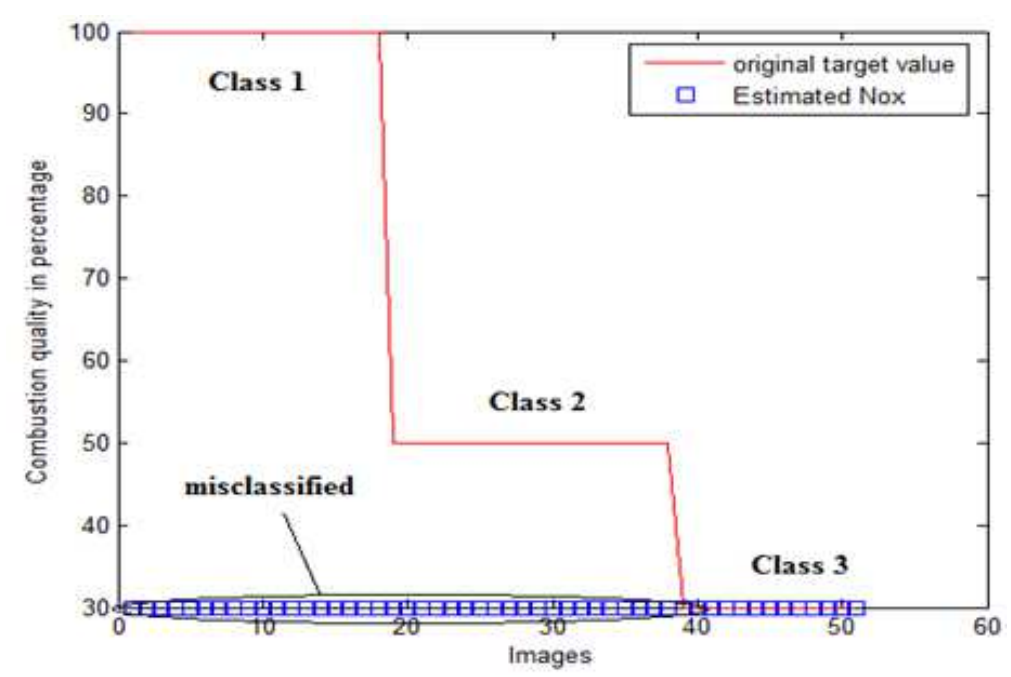

(g)

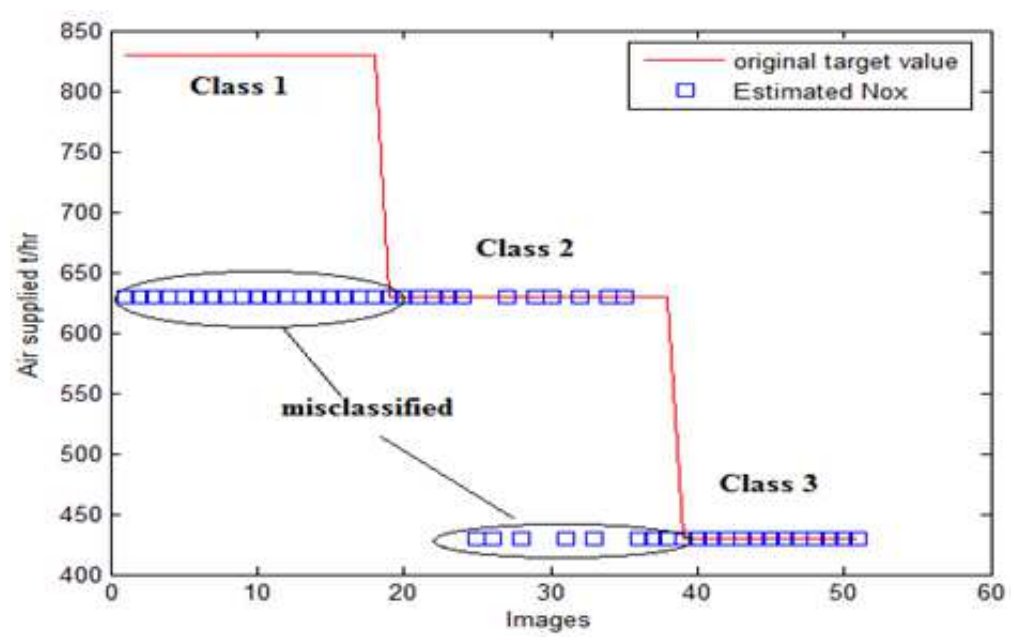

(h)

Fig. 11: Effect of changing the feature inputs to the PRBFBPA with 3 features as input to BPA and 4 features as input to RBF (a) Prediction of $\mathrm{NO}_{\mathrm{x}}$ emissions (b) Prediction of $\mathrm{NO}_{\mathrm{x}}$ emissions (c) Prediction of SOx emissions (d) Prediction of flame Temperature (e) Prediction of Fuel supplied (f) Prediction of $\mathrm{CO}_{2}$ emissions (g) Prediction Combustion quality (h) Prediction of Air supplied

The inputs for PRBFBPA are trained with 7 features as inputs. A set of final weights are obtained by training PRBFBPA with desired target values (temperature, combustion quality, $\mathrm{SO}_{\mathrm{x}}, \mathrm{CO}_{2}, \mathrm{NO}_{\mathrm{x}}, \mathrm{CO}$, rate of air and fuel supply). The effect of changing the feature set is illustrated in Figure 10 and 11.

\section{Discussion}

The analysis of various combinations of features as inputs to the parallel architecture of RBF and BPA are also done. It is inferred that the classification performance was comparatively good when three features are given as inputs to BPA and remaining four features are given as inputs to RBF. The Table 6 denotes the precision and recall values for various intelligent algorithms. Table $7 \mathrm{a}$ and $7 \mathrm{~b}$ shows the classification performance for the feature combinations for the feature set $(3,4)$.

The misclassification was high when compared with the other combinations of the features (two features as inputs to BPA and five features as inputs to RBF, two features as inputs to RBF and five features as inputs to BPA). When only one feature was given as input to BPA and remaining six features as input to RBF the networks did not converge. Similarly an analysis was made by using parallel architecture of dual RBF with combination of two, three, four and five features as inputs to the first RBF network and five, four, three and two features as inputs to the second RBF network. The outputs for dual 
RBF considering four features as input to $\mathrm{RBF}_{1}$ and three features as input to $\mathrm{RBF}_{2}$ also yields results which are misclassified. Likewise the outputs for dual RBF considering three features as input to $\mathrm{RBF}_{1}$ and four features as input to $\mathrm{RBF}_{2}$ show that almost all the patterns are misclassified.

Table 6: Performance measures for classification by FLD, RBF and PRBFBPA

\begin{tabular}{|c|c|c|c|c|c|c|}
\hline \multirow[b]{2}{*}{$\begin{array}{l}\text { Type of } \\
\text { algorithm }\end{array}$} & \multicolumn{3}{|c|}{ Precision } & \multicolumn{3}{|l|}{ Recall } \\
\hline & Class 1 & Class 2 & Class 3 & Class 1 & Class 2 & Class 3 \\
\hline FLD & 0.94 & 0.900 & 1.000 & 1 & 1 & 1 \\
\hline RBF & 1.00 & 0.900 & 0.076 & 1 & 1 & 1 \\
\hline PRBFBPA & 1.00 & 0.894 & 0.850 & 1 & 1 & 1 \\
\hline
\end{tabular}

Table 7a: Effect of changing the input features to the parallel architecture of BPA and RBF

Parallel architecture of BPA and RBF with 3 and 4

\begin{tabular}{lll} 
No. of images classified correctly for CO emissions \\
\hline Class 1 & Class 2 & Class 3 \\
18 & 16 & 13 \\
18 & 16 & 13 \\
18 & 16 & 13 \\
14 & 0 & 0 \\
0 & 18 & 0 \\
0 & 13 & 0 \\
12 & 0 & 2 \\
0 & 13 & 2 \\
10 & 0 & 3 \\
12 & 0 & 2 \\
3 & 8 & 1 \\
0 & 11 & 0 \\
10 & 2 & 1 \\
5 & 5 & 0 \\
1 & 6 & 2 \\
9 & 5 & 2 \\
2 & 5 & 2 \\
2 & 4 & 3 \\
\hline
\end{tabular}

features as inputs respectively

Feature set Centroid $\mathrm{X}$, centroid $\mathrm{Y}$ and orientation as inputs to

BPA with $\Phi 1, \Phi 2$, average intensity and area as input to RBF network

Feature set Centroid X, centroid $\mathrm{Y}$ and area as inputs to BPA with $\Phi 1$, $\Phi 2$, average intensity and orientation as input to RBF network

Feature set Centroid X, centroid $\mathrm{Y}$ and average intensity as inputs to BPA with $\Phi 1, \Phi 2$, orientation and area as input to RBF network

Feature set $\Phi 1, \Phi 2$ and area as inputs to BPA with centroid $\mathrm{X}$, centroid $\mathrm{Y}$, average intensity and orientation as input to RBF network

Feature set $\Phi 1, \Phi 2$ and orientation as inputs to BPA with centroid X, centroid $\mathrm{Y}$, average intensity and area as input to RBF network

Feature set $\Phi 1, \Phi 2$ and average intensity as inputs to BPA with centroid $\mathrm{X}$, centroid $\mathrm{Y}$, orientation and area as input to RBF network

Table 7b: Effect of changing the input features to parallel architecture of BPA and RBF

No. of images classified correctly for NOx emissions and combustion quality

Parallel architecture of BPA and RBF with 3 and 4

features as inputs respectively

Feature set Centroid $\mathrm{X}$, centroid $\mathrm{Y}$ and orientation as inputs to BPA with $\Phi 1, \Phi 2$, average intensity and area as input to RBF network Feature set Centroid X, centroid Y and area as inputs to BPA with $\Phi 1$, $\Phi 2$, average intensity and orientation as input to RBF network

\begin{tabular}{lll}
\hline Class 1 & Class 2 & Class 3 \\
\hline 18 & 16 & 13 \\
18 & 16 & 13 \\
11 & 0 & 0 \\
0 & 0 & 0 \\
11 & 0 & 0 \\
1 & 0 & 0 \\
9 & 5 & 0 \\
6 & 3 & 0 \\
10 & 4 & 0 \\
5 & 2 & 0 \\
10 & 2 & 2 \\
3 & 1 & 2
\end{tabular}


Table 8a: Choice of the parallel architecture based on Flame image classification for $\mathrm{CO}, \mathrm{CO}_{2}$ and $\mathrm{SO}_{\mathrm{x}}$ emissions

Various combinations of Intelligent Classifier with variations in feature set for combustion quality and flue gas monitoring

Parallel architecture of BPA and RBF with 3 and 4

features as inputs respectively

No. of images classified for $\mathrm{CO}, \mathrm{CO}_{2}$ and $\mathrm{SO}_{\mathrm{x}}$ emissions

Parallel architecture of BPA and RBF with 4 and 3

features as inputs respectively

Parallel architecture of multiple BPA with 4 and 3

features as inputs respectively

Parallel architecture of multiple BPA with 3 and 4 features as inputs respectively

Parallel architecture of multiple RBF with 4 and 3

features as inputs respectively

\begin{tabular}{lll}
\hline No. of images classified for $\mathrm{CO}, \mathrm{CO}_{2}$ and $\mathrm{SO}_{\mathrm{x}}$ emissions \\
\hline$-\mathrm{Class}$ Class 2 & Class 3 \\
\hline 18 & 16 & 13 \\
18 & 16 & 13 \\
18 & 16 & 13 \\
9 & 5 & 2 \\
2 & 5 & 3 \\
2 & 4 & 2 \\
4 & 10 & 1 \\
5 & 10 & 1 \\
5 & 6 & 2 \\
4 & 10 & 1 \\
5 & 10 & 1 \\
5 & 6 & 0 \\
6 & 7 & 0 \\
6 & 7 & 0 \\
4 & 8 & 0 \\
5 & 4 & 0 \\
5 & 4 & 0 \\
3 & 5 & 0 \\
0 & 3 & 0 \\
0 & 3 & 0 \\
0 & 3 &
\end{tabular}

Parallel architecture of multiple RBF with 3 and 4 features as inputs

Single RBF Classifier

Table 8b: Choice of the parallel architecture based on Flame image classification for NOx emissions and combustion quality

\begin{tabular}{|c|c|c|c|}
\hline \multirow{2}{*}{$\begin{array}{l}\text { Various combinations of Intelligent Classifier with variations } \\
\text { in feature set for combustion quality and flue gas monitoring }\end{array}$} & \multicolumn{3}{|c|}{$\begin{array}{l}\text { No. of images classified for NOx } \\
\text { emissions and combustion quality }\end{array}$} \\
\hline & Class 1 & Class 2 & Class 3 \\
\hline \multirow[t]{2}{*}{ Parallel architecture of BPA and RBF with 3 and 4 features as inputs respectively } & 18 & 16 & 13 \\
\hline & 18 & 16 & 13 \\
\hline \multirow[t]{2}{*}{ Parallel architecture of BPA and RBF with 4 and 3 features as inputs respectively } & 9 & 4 & 2 \\
\hline & 7 & 9 & 3 \\
\hline \multirow[t]{2}{*}{ Parallel architecture of multiple BPA with 4 and 3 features as inputs respectively } & 5 & 8 & 1 \\
\hline & 2 & 3 & 4 \\
\hline \multirow[t]{2}{*}{ Parallel architecture of multiple BPA with 3 and 4 features as inputs respectively } & 5 & 8 & 1 \\
\hline & 2 & 3 & 4 \\
\hline \multirow[t]{2}{*}{ Parallel architecture of multiple RBF with 4 and 3 features as inputs respectively } & 5 & 3 & 0 \\
\hline & 5 & 3 & 0 \\
\hline \multirow[t]{2}{*}{ Parallel architecture of multiple RBF with 3 and 4 features as inputs } & 5 & 5 & 0 \\
\hline & 2 & 4 & 2 \\
\hline \multirow[t]{2}{*}{ Single RBF Classifier } & 0 & 3 & 0 \\
\hline & 0 & 3 & 0 \\
\hline
\end{tabular}

Table 9: Classification performance metrics for intelligent classifiers

$\mathrm{CO}, \mathrm{CO}_{2}, \mathrm{SO}_{\mathrm{x}}$ and $\mathrm{NO}_{\mathrm{x}}$ emissions

\begin{tabular}{lll} 
Flue gas emissions & Category & Precision \\
\hline Single RBF & Class1 & 0.0390 \\
& Class2 & 0.0196 \\
Multiple RBF & Class 3 & 0.0000 \\
& Class1 & 0.0789 \\
& Class2 & 0.1960 \\
Multiple BPA & Class 3 & 0.0392 \\
& Class1 & 0.0390 \\
RBF+BPA & Class2 & 0.1176 \\
& Class 3 & 0.0196 \\
& Class1 & 1 \\
& Class2 & 1 \\
& Class 3 & 1 \\
& & 1 \\
& & 1 \\
\end{tabular}


Table 10a: Temperature, Combustion quality, $\mathrm{CO}$ and $\mathrm{CO}_{2}$ measurement

\begin{tabular}{|c|c|c|c|c|}
\hline $\begin{array}{l}\text { Combustion } \\
\text { quality/category }\end{array}$ & Image & $\begin{array}{l}\text { Flame Temperature } \\
\text { (deg Celsius) }\end{array}$ & $\begin{array}{l}\text { CO emission } \\
\text { in }(\mathrm{ppm})\end{array}$ & $\begin{array}{l}\mathrm{CO}_{2} \text { Emission } \\
\mathrm{Nm}^{3} / \mathrm{hr}\end{array}$ \\
\hline Class1 Complete combustion & $=$ & 1250 & 120 & 430 \\
\hline Class 2 Partial combustion & & 750 & 150 & 740 \\
\hline Class 3 Incomplete combustion & & 370 & 220 & 1100 \\
\hline
\end{tabular}

Table 10b: Combustion quality, $\%$ excess $\mathrm{O}_{2}$ and $\mathrm{NO}_{\mathrm{x}}$ measurement

\begin{tabular}{lllll}
\hline Combustion quality/category & $\begin{array}{l}\mathrm{NOx} \text { emission } \\
\mathrm{mg} / \mathrm{Nm}^{3}\end{array}$ & $\begin{array}{l}\mathrm{SO}_{\mathrm{x}} \text { emission } \\
\mathrm{mg} / \mathrm{Nm}^{3}\end{array}$ & $\begin{array}{l}\text { Temperature of superheated } \\
\text { steam in (deg Celsius) }\end{array}$ & $\begin{array}{l}\text { Excess } \mathrm{O}_{2} \\
\text { emissions (\%) }\end{array}$ \\
\hline Class1 Complete combustion & 75 & 410 & 530 & 4 \\
Class 2 Partial combustion & 130 & 620 & 240 & 10 \\
Class 3 Incomplete combustion & 240 & 950 & 170 & 16 \\
\hline
\end{tabular}

For the outputs for a single RBF with all the seven features as inputs the images in class 3 corresponding to incomplete combustion category were misclassified. Similarly choosing two BPA networks were also not suitable as there is much of deviation between the target and the actual values. For this combination of the intelligent network also the various combination of features as inputs were also tried. The results obtained were not promising. Hence it was finally decided to operate the intelligent parallel architecture with three features as input to BPA and remaining four features as input to RBF and finally the outputs of this combination was given as input to the RBF in the second stage to classify the patterns based on the combustion quality.

The Table $8 \mathrm{a}$ and $8 \mathrm{~b}$ illustrate that the number of images misclassified for various combinations the parallel architectures yield very less number of images to be classified correctly. The Table 9 gives the classification performance metrics for the combination of various intelligent classifiers considering three features and four features as inputs to BPA and RBF respectively. Similarly the performance metrics for various combinations of the intelligent classifiers with the feature set $(2,5),(4,3)$, $(5,2)$ as inputs to BPA and RBF was calculated and is found to be below the admissible limit. The combination of network 1 as BPA and network 2 as RBF with the final network, RBF combining the outputs of the BPA and RBF and the inputs as three features to BPA and four features to RBF in the first stage yields better results.

\section{Validation of the Parallel Architecture using BPA and RBF}

The validation of parallel architecture of BPA and $\mathrm{RBF}$ using three features as input to BPA and remaining four features as input to RBF was done. Table 10a and $10 \mathrm{~b}$ given below shows the data collected from NLC at some other period of time.

\section{Conclusion and Future Scope}

There is a further scope to extend the work by considering the spectrum of the flame images in the set of extracted features. This work is carried out by collecting the flame images pertaining to only three different combustion conditions like complete, partial and incomplete combustion conditions. The intermediate combustion conditions (like less partial, highly partial, less incomplete and highly incomplete) apart of complete condition can also be added to the source data so as to make the combustion condition and flue gas emission analysis more efficient. The integration of these simulation results with the DCS in real time for online monitoring of the flue gas emissions and combustion quality can also be carried out. Then the proposed intelligent algorithms can be used for the automation of the power plant. The inferred parameters are displayed in the centralized control room (cost effective solution).

The results in Table 11 support that the parallel architecture of the intelligent classifiers are beneficial for combustion quality monitoring in power stations since the training and testing results are very close to the validation results. The precision and recall for all the three classes are shown in Table 11.

In this work, 102 flame images collected (51 for training and 51 for testing) from the control room for a boiler in the power station and forty nine images out of them were identified to be correct. The images are pre-processed and features are extracted. The extracted features are the input to Fisher's linear discriminant function to transform the $n$-dimensional feature size into $2 \mathrm{D}$ vectors. 
Table 11: Comparison of performance criteria for testing and validation

\begin{tabular}{|c|c|c|c|c|c|c|}
\hline \multirow{2}{*}{$\begin{array}{l}\text { Comparison } \\
\text { Testing/Validation }\end{array}$} & \multicolumn{3}{|l|}{ Recall } & \multicolumn{3}{|c|}{ Precision } \\
\hline & Class 1 & Class 2 & Class 3 & Class 1 & Class 2 & Class 3 \\
\hline Testing results & 1 & 1 & 1 & 1 & 0.894 & 0.85 \\
\hline Validation results & 1 & 1 & 1 & 1 & 0.8358 & 0.8 \\
\hline
\end{tabular}

Training of RBF and BPA was done with 51 images taken from class 1; class 2 and class 3 images and finally the outputs from these networks are combined and given as the input to another RBF so as to obtain the final output. Testing and validation results shown in Table 11 indicate that PRBFBPA gives maximum classification performance when compared to FLD, RBF and PRBFBPA. Classification performance can be improved by further pre-processing of the acquired images. Depending on the quality of combustion corresponding to the colour of the flame images necessary action is taken to increase or decrease the air supply so as to ensure complete combustion. In this work by continuously monitoring the flame images, combustion quality was inferred (complete/partial/incomplete combustion). From the combustion quality the air/fuel ratio can be automatically varied. Moreover in the existing set-up measurements like $\mathrm{SO}_{\mathrm{x}}, \mathrm{NO}_{\mathrm{x}}, \mathrm{CO}$ and $\mathrm{CO}_{2}$ are inferred from the samples that are collected periodically or by using gas analyzers (expensive). The proposed algorithm can be integrated with the Distributed Control System (DCS) that is used for automation of the power plant. The inferred parameters can be displayed in the centralized control room (cost effective solution). To conclude with there is a further scope to extend the work by considering the spectrum of the flame images.

\section{Author's Contributions}

Nallamilli P.G. Bhavani: Data collection along with video from Neyveli.

Kesavan Sujatha: Intellectual input, designs protocols followed in the stydy.

Ponmagal Rajendran: Manuscript drafting.

\section{Ethics}

This article is original and contains unpublished material. The corresponding author confirms that all of the other authors have read and approved the manuscript and there are no ethical issues involved.

\section{References}

Er, M.J., S. Wu, J. Lu and H.L. Toh, 2002. Face recognition with Radial Basis Function (RBF) Neural networks. IEEE Trans. Neural Netw., 13: 697-910. DOI: 10.1109/TNN.2002.1000134
Fisher, R.A., 1936. The use of multiple measurements in taxonomic problems. Ann. Eugen., 7: 178-188. DOI: $10.1111 /$ j.1469-1809.1936.tb02137.x

Foley D.H., 1972. Considerations of sample and feature size. IEEE Trans. Inform. Theory, 18: 626-681. DOI: $10.1109 /$ TIT.1972.1054863

Han, P., X. Zhang, C. Zhen and B. Wang, 2006. Boiler flame image classification based on hidden Markov model. Proceedings of the IEEE International Symposium on Industrial Electronics, Jul. 9-13, IEEE Xplore Press, pp: 9-12.

DOI: 10.1109/ISIE.2006.295522

Hong, Z.Q. and Y.J. Yang, 1991. Optimal discriminant plane for a small number of samples and design method of classifier on the plane. Patt. Recognit., 24: 317-324. DOI: 10.1016/0031-3203(91)90074-F

Jiang, F., S. Liu, S. Liang, Z. Li and X. Wang et al., 2009. Visual flame monitoring system based on two-color method. J. Thermal Sci., 18: 284-284. DOI: $10.1007 / \mathrm{s} 11630-009-0284-1$

Lippmann, R.P., 1987. An introduction to computing with neural nets. IEEE Trans. Acoust. Speech Signal Process. Magazine, 35: 4-22.

DOI: 10.1109/MASSP.1987.1165576

Lu, G., G. Gilabert and Y. Yan, 2005. Vision based monitoring and characterisation of combustion flames. J. Phys., 15: 194-200. DOI: $10.1088 / 1742-6596 / 15 / 1 / 033$

Purushothaman, S. and Y.G. Srinivasa, 1998. A procedure for training an artificial neural network with application to tool wear monitoring. Int. J. Product. Res., 36: 635-651. DOI: 10.1080/002075498193615

Purushothaman, S., 2009. Tool wear monitoring using artificial neural network based on extended Kalman filter weight updation with transformed input patterns. J. Intell. Manufact., 21: 717-730. DOI: $10.1007 / \mathrm{s} 10845-009-0249-\mathrm{y}$

Sujatha, K. and N. Pappa, 2010. Temperature and combustion quality control in power station boilers using artificial neural networks. Proceedings of the 1st Amrita ACM-W Celebration on Women in Computing in India, Sept. 16-17, ACM, Coimbatore, India. DOI: 10.1145/1858378.1858382

Sujatha, K. and N. Pappa, 2011a. Combustion monitoring of a water tube boiler using a discriminant radial basis network. ISA Trans., 50: 101-110. DOI: $10.1016 /$ j.isatra.2010.08.006 
Sujatha, K. and N. Pappa, 2011b. Combustion quality monitoring in PS boilers using discriminant RBF, ISA. Transactions, 2: 2623-2631.

Sujatha, K., 2012. Flame monitoring in power station boilers using image processing. ICTACT J. Image Video Process., 2: 427-434.

Sujatha, K., 2013. Monitoring power station boilers using ANN and image processing. Adv. Mater. Res., 631-632: 1154-1159.

DOI: $\quad$ 10.4028/www.scientific.net/AMR.631632.1154

Sujatha, K., M. Kumaresan, R.S. Ponmagal and P. Vidhushini, 2015. Vision based automation for flame image analysis in power station boilers. Austral. J. Basic Applied Sci., 9: 40-45.

Sujatha, K., N. Pappa and A. Kalaivani, 2011. Soft sensor for flue gas monitoring in power station boilers. Proceedings of the International Conference on Process Automation Control and Computing, Jul. 20-22, IEEE Xplore Press, pp: 1-6. DOI: 10.1109/PACC.2011.5979031

Sujatha, K., N. Pappa, U. Siddharth Nambi, C.R. Raja Dinakaran and K. Senthil Kumar, 2014. Intelligent parallel networks for combustion quality monitoring in power station boilers. Adv. Mater. Res., 699: 893-899. DOI: 10.4028/www.scientific.net/AMR.699.893
Sujatha, K., N. Pappa, U.S. Nambi, K.S. Kumar and C.R. Raja Dinakaran, 2013. Automation of combustion monitoring in boilers using discriminant radial basis network. Int. J. Artificial Intell. Soft Comput., 3: 257-275.

DOI: 10.1504/IJAISC.2013.053406

Sujathal, K. and N. Pappa, 2011. Flame image analysis for combustion quality estimation in power station boilers using classification algorithms. Proceedings of the International Conference on Sustainable Energy and Intelligent Systems, Jul. 20-22, IEEE Xplore Press, pp: 795-798.

DOI: $10.1049 / \mathrm{cp} .2011 .0473$

Wojcik, W., 2008. Application of Fibre-optic flame monitoring systems to diagnostics of combustion process in power boilers. Bull. Polish Acad. Sci. 